\title{
BIOCHEMICAL CHANGES ACCOMPANYING THE INGESTION OF A CARBOXYLIC CATION EXCHANGER IN THE HYDROGEN, AMMONIUM, SODIUM, POTASSIUM, OR CALCIUM FORM
}

\author{
By L. GREENMAN, J. H. PETERS, F. M. MATEER, F. A. WEIGAND, D. WILKINS, \\ R. TARAIL, G. RHODES, AND T. S. DANOWSKI \\ (From the Department of Research Medicine, the Renziehausen Foundation, and the Children's \\ and Presbyterian Hospitals of the University of Pittsburgh School of Medicine, \\ Pittsburgh, $P a$.)
}

(Submitted for publication April 23, 1951; accepted July 9, 1951)

Preceding studies from this laboratory have defined certain changes in body fluids in dogs (1) and, in preliminary form, in human subjects $(2,3)$ accompanying the ingestion of carboxylic cation exchangers in the hydrogen cycle. In general, hyperchloremia appeared in both groups, the serum bicarbonate was lowered, and the stool output of sodium and potassium increased whereas chloride and nitrogen excretion did not change. In this paper further studies of the resins in various forms in human subjects are reported as a basis for a more adequate understanding of factors contributing to or limiting the clinical utility of these compounds.

\section{MATERIALS AND METHODS}

Carboxylic cation exchangers in the hydrogen, ammonium, potassium, sodium, or calcium form have been tested in children and adults with a variety of diseases. Selection of the patients was based primarily on willingness and ability to cooperate in the study. Edema was present in some. The experimental procedures, analytical techniques, and statistical treatment have been detailed in the animal studies mentioned earlier (1). The patients were usually but not invariably maintained on a milk formula or on a diet not rigidly restricted as to sodium content. Again it should be emphasized that all stools included in the study were formed.

\section{RESULTS}

\section{A. Effects of hydrogen or ammonium cycle resin ingestion}

From Tables I and II and the summary of mean changes in Figure 1, it is evident that the alterations in serum constituents accompanying comparable average daily intakes of these two agents, 39.7 and $38.3 \mathrm{~g}$. respectively, are essentially indistinguishable. Hyperchloremia, and lowered serum bicarbonate and potassium values developed in both groups of subjects without a statistically significant change in serum sodium. Other measured constituents of serum or blood were not affected. The mean output of sodium and of potassium per day, per unit of stool mass, and per gram of stool nitrogen (Tables III, IV, and Figure 2) rose without alteration in the excretion of chloride or nitrogen via this route.

Ingestion of the hydrogen form resin was accompanied by an increase in the average daily urine volumes without statistically significant variation in the total daily output of the various urinary constituents (Table V). In general the external balances of chloride and of sodium (Table VI) remained positive during resin therapy except in those periods in patients WK, CSc, and GDe, when edema was being delivered and in VG when the body weight was decreasing on a reducing diet. Usually simultaneous declines were recorded in both the chloride space and the extracellular sodium of these subjects. Cell nitrogen balances remained positive during resin therapy save for the obese patient, VG, who was on a limited caloric intake. With but few exceptions losses of potassium from cells coincided with and were induced by hydrogen form resin therapy. The most striking losses occurred in CSc. In the experiments with the ammonium form of the resin it is to be noted that cell potassium balances remained positive during resin therapy (Table VII). Since the stool excretion of this element had increased significantly it is obvious that the intake of this electrolyte had been more than adequate to prevent negative balances.

It is to be noted in addition that in patient SB who received cortisone as well as the ammonium form of the resin a decrease in serum carbon dioxide content and abnormally low serum potassium concentrations occurred (Table II) together with 
marked increases in stool sodium and potassium excretion (Table IV and Figure 2).

\section{B. Changes during sodium or potassium cycle resin administration}

Neither of these resins produced any statistically significant changes in the mean values for carbon dioxide content, chloride, sodium, potassium, calcium or water, although serum inorganic phos- phorus rose slightly when the potassium form of the resin was ingested (Figure 1, Tables VIII and IX). On the other hand in subjects CSt and CSc (Table IX) the serum potassium rose to hyperkaliemic levels, 6.1 meq./1., during therapy with the cation exchanger in the potassium form. In addition in CSc the extracellular potassium increased. Comparable data are not available for the other patient.

TABLE I

Body weight and analyses of blood and serum in subjects receiving the cation exchanger in the $H$ cycle

\begin{tabular}{|c|c|c|c|c|c|c|c|c|c|c|c|c|c|}
\hline subject & $\operatorname{Tim}$ & Therapy & Body wet. & $B 10$ & ००० & & & & Servan & & & & \\
\hline$(A \operatorname{ce}-\operatorname{Sex})$ & (Days) & $\left(\mathrm{g} . / d_{0}\right)$ & (ks.) & \begin{tabular}{|l|} 
Sucar \\
(an-s)
\end{tabular} & (n) & 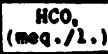 & $\begin{array}{c}C 1 \\
(m p \cdot 11 .)\end{array}$ & $\left.{ }_{(m a}^{M a}, / 2,1\right)$ & $\begin{array}{c}x \\
(\operatorname{meg} \cdot / 12 .)\end{array}$ & $\left(\begin{array}{c}c \\
(n-\infty)\end{array}\right.$ & $\left(\begin{array}{l}P \\
(3-3)\end{array}\right.$ & $\left(\begin{array}{c}40.0 \\
(3.12 .)\end{array}\right.$ & $\begin{array}{l}\text { Protels: } \\
(\text { (c.s) }\end{array}$ \\
\hline $\begin{array}{l}12 \text { n } \\
12 \text { DLabetes }\end{array}$ & $\begin{array}{r}0 \\
0-3 \\
3-6 \\
6-9 \\
2-12 \\
\end{array}$ & $\begin{array}{r}0 \\
0 \\
0 \\
25 \\
35\end{array}$ & $\begin{array}{l}32.6 \\
33.0 \\
32.6 \\
32.8 \\
33.2 \\
\end{array}$ & $\begin{array}{l}325 \\
\dot{2} \\
289 \\
236 \\
\end{array}$ & $\begin{array}{l}34 \\
34 \\
32 \\
33 \\
32\end{array}$ & $\begin{array}{l}23.4 \\
25.4 \\
25.9 \\
21.9 \\
20.4 \\
\end{array}$ & $\begin{array}{r}97.8 \\
95.4 \\
105.6 \\
106.1 \\
204.8 \\
\end{array}$ & $\begin{array}{l}136 \\
141 \\
144 \\
142 \\
138 \\
\end{array}$ & $\begin{array}{l}4.8 \\
5.0 \\
4.4 \\
4.3 \\
4.6 \\
\end{array}$ & $\begin{array}{r}10.2 \\
10.8 \\
9.0 \\
9.5 \\
- \\
\end{array}$ & $\begin{array}{l}5.2 \\
5.3 \\
6.1 \\
4.9 \\
.\end{array}$ & $\begin{array}{l}928 \\
930 \\
935 \\
929 \\
935\end{array}$ & $\begin{array}{l}8.0 \\
7.5 \\
6.7 \\
7.2 \\
7.9\end{array}$ \\
\hline $\begin{array}{l}\text { CAS } \\
9 \text { F } \\
\text { D1abetes }\end{array}$ & $\begin{array}{r}0 \\
0-3 \\
3-6 \\
6-9 \\
9-12 \\
\end{array}$ & $\begin{array}{r}0 \\
0 \\
0 \\
25 \\
35\end{array}$ & $\begin{array}{l}41.6 \\
41.6 \\
40.8 \\
40.6 \\
42.2\end{array}$ & $\begin{array}{c}166 \\
\vdots \\
\vdots \\
131\end{array}$ & $\begin{array}{l}35 \\
31 \\
34 \\
31 \\
32 \\
\end{array}$ & $\begin{array}{l}25.0 \\
25.8 \\
25.0 \\
22.6 \\
20.7 \\
\end{array}$ & $\begin{array}{l}103.4 \\
102.8 \\
104.5 \\
108.3 \\
108.9\end{array}$ & $\begin{array}{l}245 \\
143 \\
147 \\
244 \\
141\end{array}$ & $\begin{array}{l}4.5 \\
4.7 \\
3.9 \\
5.3 \\
4.1 \\
\end{array}$ & $\begin{array}{c}- \\
9.8 \\
9.2 \\
9.6 \\
- \\
\end{array}$ & $\begin{array}{l}5.7 \\
5.2 \\
4.8 \\
5.2 \\
5.6\end{array}$ & $\begin{array}{l}99 \\
96 \\
999 \\
934 \\
933\end{array}$ & $\begin{array}{l}7.9 \\
7.7 \\
7.3 \\
8.7\end{array}$ \\
\hline $\begin{array}{l}v G \\
14 Y \\
\text { Coesity }\end{array}$ & $\begin{array}{r}0 \\
0-3 \\
3-6 \\
6-9 \\
9-12 \\
12-15 \\
15-18 \\
18-21 \\
21-24 \\
24-27 \\
\end{array}$ & $\begin{array}{r}0 \\
0 \\
0 \\
0 \\
32 \\
32 \\
32 \\
0 \\
0 \\
0 \\
\end{array}$ & $\begin{array}{l}144.0 \\
145.1 \\
144.6 \\
143.1 \\
241.5 \\
141.0 \\
139.8 \\
138.2 \\
136.8 \\
135.5\end{array}$ & $\begin{array}{l}72 \\
68 \\
75 \\
78 \\
80 \\
72 \\
80 \\
\vdots \\
\vdots \\
\end{array}$ & $\begin{array}{l}29 \\
32 \\
21 \\
24 \\
24 \\
25 \\
25 \\
33 \\
30 \\
33 \\
\end{array}$ & $\begin{array}{l}29.7 \\
21.8 \\
22.9 \\
22.6 \\
18.7 \\
27.5 \\
29.5 \\
22.8 \\
23.7 \\
21.6 \\
\end{array}$ & $\begin{array}{r}105.2 \\
105.6 \\
102.1 \\
100.8 \\
106.9 \\
110.2 \\
107.7 \\
103.5 \\
101.0 \\
98.5\end{array}$ & $\begin{array}{l}147 \\
156 \\
142 \\
139 \\
135 \\
141 \\
139 \\
145 \\
142 \\
142\end{array}$ & $\begin{array}{l}4.5 \\
4.8 \\
4.3 \\
4.3 \\
4.5 \\
4.2 \\
3.9 \\
4.3 \\
4.7 \\
3.9\end{array}$ & $\begin{array}{c}10.3 \\
10.1 \\
9.9 \\
10.8 \\
- \\
10.9 \\
10.3 \\
10.8 \\
11.0\end{array}$ & $\begin{array}{l}3.8 \\
0.5 \\
3.5 \\
3.3 \\
3.9 \\
4.9 \\
4.8 \\
0\end{array}$ & $\begin{array}{l}: \\
931 \\
930 \\
\vdots \\
\dot{9} 26 \\
930 \\
926 \\
94\end{array}$ & $\begin{array}{l}7.3 \\
7.0 \\
7.9 \\
7.9 \\
8.2 \\
8.2 \\
8.4 \\
7.8\end{array}$ \\
\hline $\begin{array}{l}\text { Nuc } \\
15 \text { M } \\
\text { Diabetas }\end{array}$ & $\begin{array}{r}0 \\
0-3 \\
3-6 \\
6-9 \\
9-12 \\
\end{array}$ & $\begin{array}{r}0 \\
0 \\
0 \\
40 \\
40 \\
\end{array}$ & $\begin{array}{c}44.0 \\
43.6 \\
\vdots \\
\vdots \\
\end{array}$ & $\begin{array}{l}257 \\
231 \\
266 \\
167 \\
249 \\
\end{array}$ & $\begin{array}{l}32 \\
32 \\
29 \\
33 \\
29\end{array}$ & $\begin{array}{l}22.8 \\
22.9 \\
22.9 \\
18.5 \\
16.1 \\
\end{array}$ & $\begin{array}{l}101.4 \\
103.7 \\
102.4 \\
105.9 \\
108.1 \\
\end{array}$ & $\begin{array}{l}141 \\
143 \\
136 \\
143 \\
138\end{array}$ & $\begin{array}{r}-5 \\
4.4 \\
4.8 \\
3.7 \\
4.0 \\
\end{array}$ & $\begin{array}{c}- \\
\vdots \\
10.8\end{array}$ & $\begin{array}{c}5.1 \\
- \\
4.8 \\
\end{array}$ & $\begin{array}{l}932 \\
932 \\
- \\
921 \\
933\end{array}$ & $\begin{array}{l}7.3 \\
6.8 \\
i .2 \\
\end{array}$ \\
\hline $\begin{array}{l}\text { Puc } \\
\boldsymbol{u} \mathbf{z} \\
\text { Dieberes }\end{array}$ & $\begin{array}{r}0 \\
0-3 \\
3-6 \\
6-9 \\
2-12\end{array}$ & $\begin{array}{l}0 \\
0 \\
0 \\
40 \\
10\end{array}$ & $\begin{array}{l}42.0 \\
42.0 \\
42.0 \\
42.0 \\
42.2\end{array}$ & $\begin{array}{l}171 \\
150 \\
207 \\
166 \\
209\end{array}$ & $\begin{array}{l}36 \\
35 \\
31 \\
31 \\
31\end{array}$ & $\begin{array}{l}25.9 \\
21.7 \\
24.1 \\
18.2 \\
16.9 \\
\end{array}$ & $\begin{array}{l}10 h .7 \\
108.9 \\
105.4 \\
111.8 \\
109.2\end{array}$ & $\begin{array}{l}141 \\
145 \\
145 \\
143 \\
143\end{array}$ & $\begin{array}{l}4.4 \\
4.5 \\
5.0 \\
3.7 \\
3.7\end{array}$ & $\begin{array}{l}9.4 \\
9.5 \\
-0.7 \\
9.9\end{array}$ & $\begin{array}{l}4.6 \\
0.5 \\
0 \\
4.5 \\
\end{array}$ & $\begin{array}{l}932 \\
929 \\
924 \\
931 \\
939\end{array}$ & $\begin{array}{l}7.1 \\
6.8 \\
-0.2\end{array}$ \\
\hline $\begin{array}{l}\text { un } \\
57 n \\
\text { Cong. } \\
\text { Fellure }\end{array}$ & $\begin{array}{r}0 \\
0-2 \\
2-4 \\
4-6 \\
6-8 \\
8-9 \\
9-13 \\
13-15\end{array}$ & $\begin{array}{r}0 \\
32 \\
32 \\
32 \\
32 \\
32 \\
0 \\
0 \\
\end{array}$ & $\begin{array}{l}62.9 \\
61.3 \\
59.0 \\
58.3 \\
57.5 \\
57.3 \\
58.2 \\
59.3\end{array}$ & $\begin{array}{l}70 \\
80 \\
84 \\
93 \\
83 \\
-87 \\
87 \\
- \\
\end{array}$ & $\begin{array}{l}40 \\
49 \\
51 \\
48 \\
48 \\
46 \\
47 \\
44\end{array}$ & $\begin{array}{l}28.3 \\
23.2 \\
22.4 \\
20.1 \\
19.3 \\
20.2 \\
25.9 \\
24.7 \\
\end{array}$ & $\begin{array}{l}100.5 \\
106.7 \\
106.5 \\
104.3 \\
104.8 \\
106.4 \\
101.8 \\
102.4\end{array}$ & $\begin{array}{l}142 \\
139 \\
138 \\
141 \\
142 \\
141 \\
143 \\
142 \\
\end{array}$ & $\begin{array}{l}4.6 \\
4.4 \\
3.7 \\
4.0 \\
4.4 \\
3.9 \\
4.1 \\
4.7 \\
\end{array}$ & $\begin{array}{c}11.0 \\
10.6 \\
9.8 \\
\vdots \\
10.1 \\
10.2 \\
- \\
\end{array}$ & $\begin{array}{l}3.8 \\
3.4 \\
3.3 \\
4.3 \\
3.9 \\
4.1 \\
4.4 \\
\end{array}$ & $\begin{array}{c}934 \\
934 \\
- \\
934 \\
934 \\
930 \\
934\end{array}$ & $\begin{array}{l}6.5 \\
6.3 \\
7.0 \\
7.6 \\
7.0 \\
7.4 \\
6.9\end{array}$ \\
\hline $\begin{array}{l}C 8 C \\
33 \text { P DAe. } \\
C-V \text { DIe. }\end{array}$ & $\begin{array}{r}0 \\
0-3 \\
3-6 \\
6-9 \\
9-12 \\
12-15 \\
15-19\end{array}$ & $\begin{array}{c}0 \\
0 \\
0 \\
32 \\
32 \\
0 \\
0 \\
\end{array}$ & $\begin{array}{l}48.9 \\
49.3 \\
50.9 \\
49.8 \\
49.1 \\
48.5 \\
47.9\end{array}$ & $\begin{array}{l}87 \\
88 \\
75 \\
\vdots \\
-\end{array}$ & $\begin{array}{l}33 \\
32 \\
32 \\
29 \\
29 \\
31 \\
-\end{array}$ & $\begin{array}{l}22.2 \\
25.4 \\
26.4 \\
20.5 \\
23.6 \\
23.4 \\
27.0 \\
\end{array}$ & $\begin{array}{l}20.4 \\
104.8 \\
104.4 \\
107.8 \\
106.5 \\
101.9 \\
203.6\end{array}$ & $\begin{array}{l}142 \\
137 \\
144 \\
141 \\
142 \\
139 \\
142 \\
\end{array}$ & $\begin{array}{l}5.2 \\
5.0 \\
4.7 \\
4.4 \\
4.1 \\
4.9 \\
5.4\end{array}$ & $\begin{array}{c}2.2 \\
9.7 \\
9.6 \\
9.6 \\
- \\
\end{array}$ & $\begin{array}{l}4.8 \\
5.4 \\
5.8 \\
6.2 \\
5.2 \\
.\end{array}$ & $\begin{array}{l}939 \\
941 \\
942 \\
938 \\
939 \\
928 \\
936 \\
\end{array}$ & $\begin{array}{c}6.3 \\
5.9 \\
6.2 \\
6.6 \\
\vdots \\
\end{array}$ \\
\hline $\begin{array}{l}\text { ODe } \\
34 K \\
\text { Chr. } \\
\text { Mephrit1s }\end{array}$ & $\begin{array}{r}0 \\
0-5 \\
5-10 \\
10-15 \\
15-19 \\
19-25\end{array}$ & $\begin{array}{l}0 \\
30 \\
0 \\
21 \\
20 \\
60\end{array}$ & $\begin{array}{l}67.7 \\
57.8 \\
56.4 \\
57.6 \\
56.6 \\
55.8\end{array}$ & $\begin{array}{l}: \\
\vdots \\
0\end{array}$ & $\begin{array}{l}81 \\
87 \\
80 \\
76 \\
73 \\
62\end{array}$ & $\begin{array}{l}21.5 \\
12.2 \\
14.4 \\
13.7 \\
13.7 \\
13.2\end{array}$ & $\begin{array}{l}100.6 \\
212.3 \\
108.6 \\
115.9 \\
113.8 \\
116.3\end{array}$ & $\begin{array}{l}145 \\
139 \\
235 \\
142 \\
145 \\
140\end{array}$ & $\begin{array}{l}5.2 \\
6.8 \\
5.4 \\
4.3 \\
4.0 \\
3.5\end{array}$ & $\begin{array}{l}9.2 \\
9.0 \\
9.5 \\
9.5 \\
8.7 \\
7.8 \\
\end{array}$ & $\begin{array}{l}6.3 \\
9.1 \\
7.3 \\
6.2 \\
6.3 \\
5.8 \\
\end{array}$ & $\begin{array}{l}938 \\
930 \\
931 \\
937 \\
936 \\
941\end{array}$ & $\begin{array}{l}5.5 \\
6.3 \\
6.2 \\
5.9 \\
6.4 \\
5.9\end{array}$ \\
\hline
\end{tabular}


TABLE II

Body weight and analyses of blood and serum in subjects receiving cation exchanger in the $\mathrm{NH}_{4}$ cycle

\begin{tabular}{|c|c|c|c|c|c|c|c|c|c|c|c|c|c|}
\hline \multirow{2}{*}{$\begin{array}{c}\text { Subject } \\
(A g e-S e x)\end{array}$} & \multirow{2}{*}{$\begin{array}{c}\text { Time } \\
\text { (Days) }\end{array}$} & \multirow{2}{*}{$\begin{array}{c}\text { Therapy } \\
\text { (g./d.) }\end{array}$} & \multirow{2}{*}{$\underset{(\text { kg. })}{\text { Body Wgt. }}$} & \multicolumn{2}{|c|}{ Blood } & \multicolumn{8}{|c|}{ Serum } \\
\hline & & & & $\underset{(m g m . \%)}{\text { Sugar }}$ & $\underset{(m g m . \%)}{\text { NPN }}$ & $\underset{(\text { meq./l. })}{\mathrm{HCO}_{2}}$ & $\underset{\text { (meq./l. })}{\mathrm{Cl}}$ & $\underset{(\text { meq. } / l .)}{\mathrm{Na}}$ & $\underset{(\text { meq. } / \text { l. })}{\mathbf{K}}$ & $\underset{(m g m . \%)}{\mathrm{Ca}}$ & $\underset{(m g m . \%)}{\mathbf{P}}$ & $\underset{(g . / l .)}{\mathrm{H}_{2} \mathrm{O}}$ & $\begin{array}{c}\text { Protein } \\
(\text { (. \%) }\end{array}$ \\
\hline $\begin{array}{l}\text { JF } \\
29 \text { M } \\
\text { Diabetes }\end{array}$ & $\begin{array}{l}0 \\
0-6 \\
6-12 \\
12-18 \\
18-24\end{array}$ & $\begin{array}{r}0 \\
40 \\
0 \\
40 \\
0\end{array}$ & $\begin{array}{l}69.5 \\
67.4 \\
66.6 \\
67.0 \\
68.9\end{array}$ & $\begin{array}{r}\overline{124} \\
\overline{108} \\
69\end{array}$ & $\begin{array}{l}35 \\
34 \\
41 \\
38 \\
32\end{array}$ & $\begin{array}{l}25.7 \\
27.5 \\
30.1 \\
23.7 \\
28.1\end{array}$ & $\begin{array}{r}95.9 \\
100.2 \\
98.0 \\
104.9 \\
104.0\end{array}$ & $\begin{array}{l}138 \\
150 \\
149 \\
145 \\
147\end{array}$ & $\begin{array}{l}4.5 \\
4.5 \\
4.5 \\
5.3 \\
5.0\end{array}$ & $\begin{array}{r}9.5 \\
9.8 \\
10.0 \\
9.7 \\
9.5\end{array}$ & $\begin{array}{l}3.2 \\
3.5 \\
3.6 \\
3.5 \\
4.4\end{array}$ & $\begin{array}{l}929 \\
929 \\
925 \\
925 \\
934\end{array}$ & $\begin{array}{l}7.5 \\
7.8 \\
8.1 \\
7.9 \\
7.3\end{array}$ \\
\hline $\begin{array}{l}\mathrm{CS} \\
54 \mathrm{M} \\
\text { Arthritis }\end{array}$ & $\begin{array}{l}0 \\
0-6 \\
6-7 \\
7-12\end{array}$ & $\begin{array}{r}0 \\
40 \\
0 \\
0\end{array}$ & $\frac{60.2}{-}$ & E & $\begin{array}{l}33 \\
\frac{36}{31}\end{array}$ & $\begin{array}{l}26.3 \\
14.4 \\
23.0 \\
27.6\end{array}$ & $\begin{array}{l}108.8 \\
114.5 \\
110.4 \\
101.7\end{array}$ & $\begin{array}{l}144 \\
144 \\
144 \\
145\end{array}$ & $\begin{array}{l}4.3 \\
4.1 \\
3.7 \\
4.4\end{array}$ & $\begin{array}{l}8.4 \\
8.8 \\
\frac{8.9}{}\end{array}$ & $\begin{array}{l}2.6 \\
2.3 \\
\frac{2.1}{}\end{array}$ & $\begin{array}{l}935 \\
931 \\
\frac{-}{938}\end{array}$ & $\begin{array}{l}6.6 \\
7.2 \\
- \\
-\end{array}$ \\
\hline $\begin{array}{l}\mathrm{CSc} \\
33 \mathrm{~F} \\
\mathrm{C}-\mathrm{V} \text { dis. }\end{array}$ & $\begin{array}{c}0^{*} \\
0-7 \\
7-13 \\
13-19\end{array}$ & $\begin{array}{r}* \\
8 \\
40 \\
0\end{array}$ & $\begin{array}{l}48.7 \\
48.0 \\
48.4 \\
52.7\end{array}$ & $\frac{\bar{z}}{\overline{90}}$ & $\begin{array}{l}38 \\
39 \\
41 \\
35\end{array}$ & $\begin{array}{l}29.4 \\
24.4 \\
22.8 \\
26.6\end{array}$ & $\begin{array}{r}90.8 \\
97.0 \\
101.2 \\
94.5\end{array}$ & $\begin{array}{l}142 \\
140 \\
153 \\
136\end{array}$ & $\begin{array}{l}6.1 \\
4.4 \\
3.8 \\
4.3\end{array}$ & $\frac{8.8}{8.8}$ & $\begin{array}{l}5.0 \\
3.8 \\
4.5\end{array}$ & $\begin{array}{l}939 \\
944 \\
933 \\
941\end{array}$ & $\frac{6.3}{6.1}$ \\
\hline $\begin{array}{l}\text { SB† } \\
7 \mathrm{~F} \\
\text { Rh. Fev. }\end{array}$ & $\begin{array}{l}0 \\
0-3 \\
3-6 \\
6-9 \\
9-12 \\
12-15 \\
15-18 \\
18-21\end{array}$ & $\begin{array}{l}\dagger \\
40 \\
40 \\
40 \\
40 \\
40 \\
40 \\
40\end{array}$ & $\begin{array}{c}28.0 \\
28.3 \\
27.9 \\
28.1 \\
28.0 \\
28.5 \\
-\end{array}$ & $\begin{array}{l}70 \\
65 \\
76 \\
78 \\
59 \\
61 \\
92\end{array}$ & $\begin{array}{l}\frac{36}{36} \\
29 \\
30 \\
32 \\
29 \\
36\end{array}$ & $\begin{array}{c}23.7 \\
28.7 \\
30.2 \\
28.1 \\
30.1 \\
\overline{27.8} \\
20.3\end{array}$ & $\begin{array}{r}106.5 \\
99.9 \\
97.1 \\
101.4 \\
99.1 \\
96.5 \\
100.7 \\
109.7\end{array}$ & $\begin{array}{l}148 \\
150 \\
144 \\
145 \\
145 \\
144 \\
150 \\
148\end{array}$ & $\begin{array}{l}4.6 \\
2.4 \\
3.4 \\
2.8 \\
2.5 \\
2.9 \\
4.8 \\
4.2\end{array}$ & $\begin{array}{c}\overline{10.1} \\
9.1 \\
- \\
- \\
= \\
-\end{array}$ & $\begin{array}{l}\overline{3.6} \\
3.5 \\
\overline{4.0} \\
3.1 \\
4.0 \\
4.4\end{array}$ & $\begin{array}{c}934 \\
938 \\
937 \\
934 \\
= \\
\overline{9} \\
-\end{array}$ & $\begin{array}{l}- \\
- \\
\overline{6.5} \\
6.7 \\
7.0 \\
-\end{array}$ \\
\hline $\begin{array}{l}\text { WY } \\
45 \mathrm{M} \\
\text { Diabetes }\end{array}$ & $\begin{array}{l}0 \\
0-6 \\
6-7 \\
7-12\end{array}$ & $\begin{array}{r}0 \\
40 \\
0 \\
0\end{array}$ & $\begin{array}{l}74.1 \\
71.7 \\
\overline{71.8}\end{array}$ & $\frac{\overline{160}}{\overline{172}}$ & $\begin{array}{l}68 \\
63 \\
63 \\
55\end{array}$ & $\begin{array}{l}23.2 \\
16.2 \\
17.5 \\
20.4\end{array}$ & $\begin{array}{l}107.7 \\
108.4 \\
111.5 \\
109.4\end{array}$ & $\begin{array}{l}138 \\
143 \\
144 \\
140\end{array}$ & $\begin{array}{l}5.1 \\
3.8 \\
4.4 \\
4.3\end{array}$ & $\begin{array}{l}9.3 \\
8.5 \\
\frac{9.6}{}\end{array}$ & $\begin{array}{l}5.0 \\
4.8 \\
\frac{4.7}{4.7}\end{array}$ & $\begin{array}{l}924 \\
921 \\
\frac{929}{929}\end{array}$ & $\begin{array}{l}7.0 \\
7.7 \\
7.3\end{array}$ \\
\hline $\begin{array}{l}\text { EMc } \\
71 \text { F } \\
\text { Diabetes }\end{array}$ & $\begin{array}{l}0 \\
0-6 \\
6-7\end{array}$ & $\begin{array}{r}0 \\
40 \\
0\end{array}$ & E & $\begin{array}{l}- \\
203 \\
-\end{array}$ & $\begin{array}{l}42 \\
46 \\
42\end{array}$ & $\begin{array}{l}27.2 \\
11.8 \\
15.2\end{array}$ & $\begin{array}{l}107.4 \\
117.2 \\
115.5\end{array}$ & $\begin{array}{l}144 \\
144 \\
145\end{array}$ & $\begin{array}{l}4.5 \\
4.0 \\
4.0\end{array}$ & $\begin{array}{l}9.1 \\
8.9 \\
-\end{array}$ & $\begin{array}{l}3.3 \\
3.0 \\
-\end{array}$ & $\begin{array}{l}926 \\
927 \\
-\end{array}$ & $\begin{array}{l}7.3 \\
8.0 \\
-\end{array}$ \\
\hline $\begin{array}{l}\text { DY } \\
12 \mathrm{M} \\
\text { Nephrosis }\end{array}$ & $\begin{array}{l}0 \ddagger \\
0-4 \\
4-10\end{array}$ & $\begin{array}{r}7 \\
35 \\
0\end{array}$ & $\begin{array}{l}30.4 \\
31.4 \\
31.4\end{array}$ & $\frac{67}{-}$ & $\begin{array}{l}44 \\
33 \\
36\end{array}$ & $\begin{array}{l}23.1 \\
19.7 \\
20.5\end{array}$ & $\begin{array}{l}108.6 \\
113.7 \\
110.1\end{array}$ & $\begin{array}{l}141 \\
140 \\
139\end{array}$ & $\begin{array}{l}3.7 \\
3.1 \\
4.0\end{array}$ & $\frac{6.7}{7.3}$ & $\begin{array}{l}5.0 \\
4.2 \\
4.5\end{array}$ & $\begin{array}{l}936 \\
938 \\
933\end{array}$ & $\begin{array}{l}3.7 \\
3.5 \\
3.6\end{array}$ \\
\hline $\begin{array}{l}\text { WG } \\
12 \text { M } \\
\text { Gl. Neph. } \\
\text { (healed) }\end{array}$ & $\begin{array}{l}0 \\
0-5 \\
5-10 \\
10-15 \\
15-20 \\
20-26 \\
26-31\end{array}$ & $\begin{array}{r}0 \\
0 \\
0 \\
0 \\
0 \\
38 \\
0\end{array}$ & $\begin{array}{l}32.4 \\
30.4 \\
28.8 \\
30.1 \\
30.1 \\
30.0 \\
29.8\end{array}$ & $\begin{array}{l}62 \\
80 \\
\overline{75} \\
- \\
-\end{array}$ & $\begin{array}{l}35 \\
43 \\
35 \\
36 \\
35 \\
37 \\
44\end{array}$ & $\begin{array}{l}25.8 \\
21.7 \\
24.9 \\
27.2 \\
26.6 \\
26.6 \\
26.6\end{array}$ & $\begin{array}{r}104.1 \\
106.7 \\
97.4 \\
100.4 \\
105.1 \\
105.0 \\
101.5\end{array}$ & $\begin{array}{l}135 \\
140 \\
138 \\
140 \\
141 \\
137\end{array}$ & $\begin{array}{l}4.5 \\
4.9 \\
5.4 \\
4.4 \\
3.8 \\
4.0\end{array}$ & $\begin{array}{c}11.5 \\
- \\
\overline{9.9} \\
9.5 \\
\overline{10.0}\end{array}$ & $\begin{array}{l}5.4 \\
5.4 \\
5.0 \\
4.8 \\
4.6 \\
\frac{}{4.6}\end{array}$ & $\begin{array}{l}936 \\
915 \\
921 \\
927 \\
930 \\
925\end{array}$ & $\begin{array}{l}6.8 \\
- \\
8.3 \\
7.7 \\
7.8\end{array}$ \\
\hline
\end{tabular}

* End of $\mathrm{K}$ resin period.

$\dagger$ Patient receiving cortisone throughout study, $100 \mathrm{mgm} . /$ day for 40 days.

$\ddagger$ End of $\mathrm{K}$ resin period.

Ingestion of the sodium cycle resin increased the stool output of potassium and of sodium (Table $\mathrm{X}$ and Figure 2). Similarly, on an intake of the potassium cycle resin, stool potassium and, to a lesser extent, stool sodium increased (Table XI and Figure 2). In each group of experiments, some of the cation, either sodium or potassium, ingested with the resin was released and entered the body fluids. Though daily urinary excretions of the particular cation under scrutiny were quite high, positive external balances were recorded (Tables XII and XIII). In the case of the sodium resin, the absorbed cation, sodium, remained primarily in the extracellular phase (Subjects EB, $\mathrm{JV}$, and VB). Potassium released from the resin on the other hand was retained in the body and entered the cellular phase in patient RC (Table XIII). Patients WG and CSc, however, excreted 
this cation in both urine and stool and lost it from cells.

\section{Studies during calcium cycle resin}

Insofar as can be determined by inspection of Table XIV or statistical comparison of mean values (Figure 2) this resin failed to influence either the stool output of chloride, or nitrogen but did raise to a slight extent the stool sodium in all cate- gories and stool potassium in the per day and per gram of nitrogen groupings. It would appear, therefore, that attachment of this divalent cation to the carboxylic exchanger renders it less effective from the point of view of affecting stool excretion of sodium and potassium. Furthermore there is no evidence of any consistent and significant change in either the individual values or the means of most of the measured serum constituents, includ-

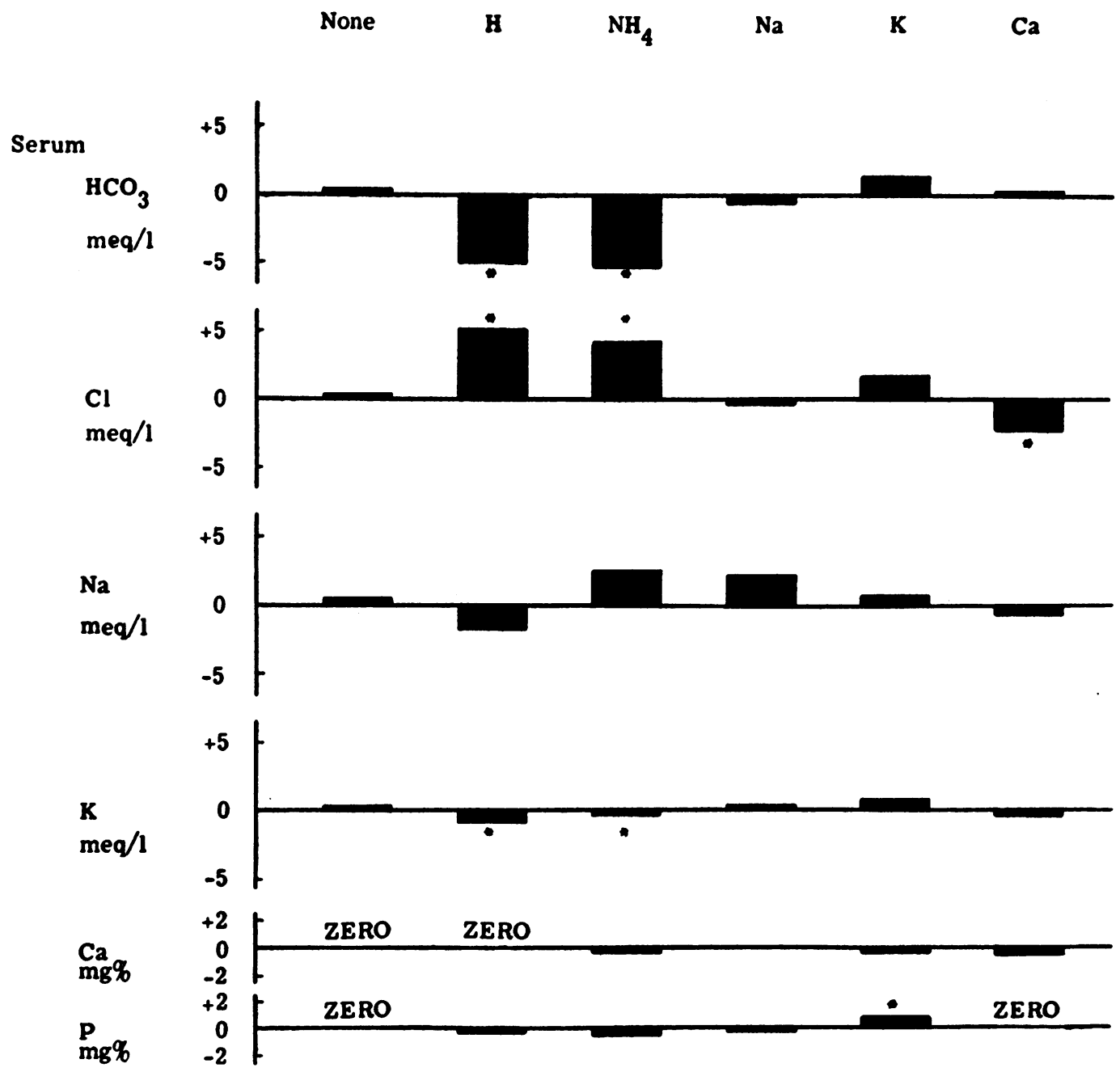

Fig. 1. Serum Electrolyte Concentrations With and Without Resin Therapy

The blocks represent mean alterations in serum constituents between the onset and the end of each of the regimens indicated at the head of the individual columns. The chemical abbreviations stand for the form of resin ingested. Asterisks identify statistically significant differences from the changes in the control values (" $p$ " for the " $t$ " test equals 0.05 or less). Without resin therapy serum constituents listed on the left varied but little. Treatment with $\mathrm{H}$ or $\mathrm{NH}_{4}$ forms produced acidosis and hyperchloremia and lowered serum potassium levels. Ingestion of the $\mathrm{Na}$ form did not produce any significant changes. Serum inorganic phosphorus rose during administration of the $\mathrm{K}$ cycle, and serum chloride fell when the $\mathrm{Ca}$ form was ingested. 
TABLE III

Intake data and urine and stool output in subjects receiving the cation exchanger in the $H$ cycle

\begin{tabular}{|c|c|c|c|c|c|c|c|c|c|c|c|c|c|c|c|c|c|}
\hline subs. & Tine & Thorapy & & & Intake & & & & & Urine & & & & & Stool & & \\
\hline & (days) & $(\mathrm{s} \cdot / \mathrm{d})$. & $\begin{array}{c}\text { Flusd } \\
(2 .)\end{array}$ & $\begin{array}{c}C 2 \\
\left(\omega_{0}\right)\end{array}$ & $\begin{array}{c}\mathrm{Ma} \\
(\mathrm{meq} .) \\
\end{array}$ & $\begin{array}{c}x \\
x=0 .) \\
\end{array}$ & (en.) & $\begin{array}{l}\text { Vol. } \\
\text { (1.) }\end{array}$ & \begin{tabular}{c|} 
Cl \\
(meg.) \\
\end{tabular} & $\begin{array}{c}\mathrm{Na} \\
\text { (neq.) }\end{array}$ & $\begin{array}{c}\mathrm{X} \\
\text { (neq.) } \\
\end{array}$ & 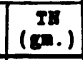 & $\begin{array}{l}\text { Met } \\
\text { (eth })\end{array}$ & $\begin{array}{c}\mathrm{Cl} \\
\text { (neq.) } \\
\end{array}$ & $\begin{array}{c}\mathrm{Ma} \\
(\operatorname{meq} .)\end{array}$ & 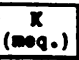 & $\left(\cos ^{n}\right)$ \\
\hline $\mathbf{W}$ & $\begin{array}{r}0-3 \\
3-6 \\
6-9 \\
9-12 \\
\end{array}$ & $\begin{array}{r}0 \\
0 \\
25 \\
35 \\
\end{array}$ & $\begin{array}{l}7.36 \\
7.11 \\
8.96 \\
9.28 \\
\end{array}$ & $\begin{array}{l}290 \\
215 \\
215 \\
215 \\
\end{array}$ & $\begin{array}{l}259 \\
180 \\
180 \\
180 \\
\end{array}$ & $\begin{array}{l}230 \\
257 \\
257 \\
257 \\
\end{array}$ & $\begin{array}{l}33.5 \\
37.4 \\
37.4 \\
37.4 \\
\end{array}$ & $\begin{array}{l}3.88 \\
3.18 \\
5.91 \\
8.30 \\
\end{array}$ & $\begin{array}{l}253 \\
115 \\
132 \\
183 \\
\end{array}$ & $\begin{array}{r}221 \\
115 \\
87 \\
91 \\
\end{array}$ & $\begin{array}{r}200 \\
195 \\
189 \\
91 \\
\end{array}$ & $\begin{array}{l}27.7 \\
28.3 \\
25.4 \\
29.2\end{array}$ & $\begin{array}{l}643 \\
563\end{array}$ & $\begin{array}{l}7 \\
8\end{array}$ & $\begin{array}{r}7 \\
118\end{array}$ & $\begin{array}{l}102 \\
319\end{array}$ & $\begin{array}{l}5.6 \\
5.1\end{array}$ \\
\hline CAS & $\begin{array}{r}0-3 \\
3-6 \\
6-9 \\
9-12\end{array}$ & $\begin{array}{r}0 \\
0 \\
25 \\
35\end{array}$ & $\begin{array}{l}6.84 \\
6.80 \\
7.79 \\
7.44 \\
\end{array}$ & $\begin{array}{r}512 \\
545 \\
568 \\
568 \\
\end{array}$ & $\begin{array}{l}481 \\
512 \\
534 \\
534 \\
\end{array}$ & $\begin{array}{l}230 \\
245 \\
256 \\
256 \\
\end{array}$ & $\begin{array}{l}33.6 \\
35.8 \\
37.3 \\
37.3\end{array}$ & $\begin{array}{l}3.48 \\
2.73 \\
2.79 \\
4.25 \\
\end{array}$ & $\begin{array}{l}447 \\
408 \\
389 \\
509 \\
\end{array}$ & $\begin{array}{l}470 \\
459 \\
340 \\
482 \\
\end{array}$ & $\begin{array}{r}170 \\
177 \\
107 \\
81 \\
\end{array}$ & $\begin{array}{l}25.0 \\
24.9 \\
23.7 \\
29.3\end{array}$ & $\begin{array}{r}55 \\
197\end{array}$ & $\begin{array}{l}1 \\
3\end{array}$ & $\begin{array}{r}3 \\
22\end{array}$ & $\begin{array}{r}9 \\
136\end{array}$ & $\begin{array}{l}0.8 \\
1.4\end{array}$ \\
\hline vo & $\begin{array}{r}0-3 \\
3-6 \\
6-9 \\
9-12 \\
12-15 \\
15-18 \\
18-21 \\
21-24 \\
24-27\end{array}$ & $\begin{array}{r}0 \\
0 \\
0 \\
32 \\
32 \\
32 \\
0 \\
0 \\
0 \\
\end{array}$ & $\begin{array}{l}5.55 \\
4.58 \\
3.58 \\
4.42 \\
4.46 \\
6.12 \\
4.40 \\
3.40 \\
4.28 \\
\end{array}$ & $\begin{array}{l}246 \\
271 \\
216 \\
205 \\
225 \\
250 \\
50 \\
41 \\
47 \\
\end{array}$ & $\begin{array}{r}231 \\
254 \\
203 \\
193 \\
192 \\
235 \\
3 \\
2 \\
3 \\
\end{array}$ & $\begin{array}{r}111 \\
122 \\
97 \\
93 \\
101 \\
113 \\
120 \\
99 \\
115 \\
\end{array}$ & $\begin{array}{l}16.2 \\
17.8 \\
14.2 \\
13.5 \\
14.8 \\
16.5 \\
14.2 \\
11.7 \\
13.5 \\
\end{array}$ & $\begin{array}{l}1.10 \\
0.50 \\
1.00 \\
1.49 \\
1.65 \\
4.58 \\
2.60 \\
3.25 \\
2.80 \\
\end{array}$ & $\begin{array}{r}215 \\
136 \\
233 \\
204 \\
240 \\
551 \\
225 \\
107 \\
50\end{array}$ & $\begin{array}{r}188 \\
139 \\
244 \\
187 \\
104 \\
280 \\
98 \\
36 \\
57\end{array}$ & $\begin{array}{l}32 \\
19 \\
82 \\
86 \\
53 \\
50 \\
28 \\
50 \\
60 \\
\end{array}$ & $\begin{array}{r}16.2 \\
5.6 \\
11.9 \\
13.1 \\
14.9 .9 \\
22.7 \\
16.2 \\
19.4 \\
15.1\end{array}$ & $\begin{array}{l}- \\
89\end{array}$ & $\begin{array}{l}3 \\
0.4\end{array}$ & $\begin{array}{l}140 \\
149 \\
28\end{array}$ & $\begin{array}{c}87 \\
104 \\
26\end{array}$ & $\begin{array}{l}5.0 \\
1.0 \\
1.0\end{array}$ \\
\hline Nic & $\begin{array}{r}0-3 \\
3-6 \\
6-9 \\
9-12\end{array}$ & $\begin{array}{r}0 \\
0 \\
40 \\
40 \\
\end{array}$ & & $\begin{array}{c}\text { Full } \\
\text { " } \\
\text { " }\end{array}$ & $\begin{array}{c}\text { diab. } \\
n \\
n\end{array}$ & $\begin{array}{c}\text { diet } \\
" \\
n\end{array}$ & & $\begin{array}{l}4.25 \\
3.75 \\
7.04 \\
3.20 \\
\end{array}$ & $\begin{array}{l}614 \\
515 \\
716 \\
299 \\
\end{array}$ & $\begin{array}{l}587 \\
638 \\
929 \\
173 \\
\end{array}$ & $\begin{array}{r}193 \\
110 \\
232 \\
69 \\
\end{array}$ & $\begin{array}{l}37.1 \\
34.9 \\
43.2 \\
32.0\end{array}$ & $\begin{array}{l}708 \\
775\end{array}$ & $\begin{array}{l}5 \\
5\end{array}$ & $\begin{array}{r}57 \\
174 \\
\end{array}$ & $\begin{array}{r}83 \\
334 \\
\end{array}$ & $\begin{array}{r}10.0 \\
8.8\end{array}$ \\
\hline Wlc & $\begin{array}{r}0-3 \\
3-6 \\
6-9 \\
9-12\end{array}$ & $\begin{array}{r}0 \\
0 \\
40 \\
40 \\
\end{array}$ & & $\begin{array}{l}\text { Full } \\
\text { n } \\
n\end{array}$ & $\begin{array}{l}\text { asab. } \\
n \\
n\end{array}$ & $\begin{array}{l}\text { diet } \\
n \\
n\end{array}$ & & $\begin{array}{l}3.76 \\
1.85 \\
5.62 \\
4.22\end{array}$ & $\begin{array}{l}458 \\
249 \\
516 \\
353\end{array}$ & $\begin{array}{l}508 \\
249 \\
337 \\
146 \\
\end{array}$ & $\begin{array}{r}140 \\
94 \\
188 \\
66 \\
\end{array}$ & $\begin{array}{l}38.5 \\
22.4 \\
42.9 \\
37.0\end{array}$ & $\begin{array}{l}494 \\
905\end{array}$ & $\begin{array}{l}5 \\
4\end{array}$ & $\begin{array}{r}11 \\
351 \\
\end{array}$ & $\begin{array}{r}44 \\
283 \\
\end{array}$ & $\begin{array}{l}7.9 \\
6.6\end{array}$ \\
\hline $\ln x$ & $\begin{array}{r}0-2 \\
2-4 \\
4-6 \\
6-8 \\
8-9 \\
9-13 \\
13-15\end{array}$ & $\begin{array}{l}32 \\
32 \\
32 \\
32 \\
32 \\
0 \\
0 \\
\end{array}$ & $\begin{array}{r}6.47 \\
6.25 \\
7.50 \\
5.79 \\
3.02 \\
13.48 \\
6.71 \\
\end{array}$ & $\begin{array}{r}83 \\
89 \\
89 \\
78 \\
44 \\
180 \\
89 \\
\end{array}$ & $\begin{array}{r}5 \\
5 \\
5 \\
5 \\
3 \\
21 \\
5 \\
\end{array}$ & $\begin{array}{l}200 \\
216 \\
216 \\
189 \\
108 \\
437 \\
216 \\
\end{array}$ & $\begin{array}{l}23.6 \\
25.4 \\
25.4 \\
22.3 \\
12.7 \\
51.5 \\
25.4\end{array}$ & $\begin{array}{l}3.96 \\
5.38 \\
3.57 \\
4.05 \\
1.70 \\
5.20 \\
0.48 \\
\end{array}$ & $\begin{array}{r}132 \\
190 \\
98 \\
92 \\
38 \\
154 \\
15 \\
\end{array}$ & $\begin{array}{r}82 \\
105 \\
31 \\
24 \\
5 \\
50 \\
3 \\
\end{array}$ & $\begin{array}{r}84 \\
93 \\
51 \\
38 \\
9 \\
73 \\
7 \\
\end{array}$ & $\begin{array}{r}14.1 \\
18.2 \\
17.1 \\
20.0 \\
8.6 \\
47.1 \\
5.7\end{array}$ & 104 & 3 & 88. & 147 & $\begin{array}{l}4.1 \\
2.6\end{array}$ \\
\hline $\csc$ & $\begin{array}{r}0-3 \\
3-6 \\
6-9 \\
9-12 \\
0-15 \\
15-19\end{array}$ & $\begin{array}{r}0 \\
0 \\
32 \\
32 \\
0 \\
0 \\
\end{array}$ & $\begin{array}{l}8.32 \\
10.26 \\
2.70 \\
12.95 \\
8.33 \\
2.43\end{array}$ & $\begin{array}{l}556 \\
567 \\
567 \\
649 \\
112 \\
166 \\
\end{array}$ & $\begin{array}{r}525 \\
532 \\
532 \\
609 \\
7 \\
10 \\
\end{array}$ & $\begin{array}{l}230 \\
256 \\
256 \\
253 \\
293 \\
272 \\
104\end{array}$ & $\begin{array}{l}33.6 \\
37.3 \\
37.3 \\
42.7 \\
32.1 \\
47.6\end{array}$ & $\begin{array}{l}4.12 \\
4.75 \\
9.70 \\
9.80 \\
5.80 \\
8.40 \\
\end{array}$ & $\begin{array}{l}446 \\
442 \\
650 \\
588 \\
247 \\
249\end{array}$ & $\begin{array}{r}269 \\
370 \\
613 \\
491 \\
101 \\
88 \\
\end{array}$ & $\begin{array}{l}184 \\
206 \\
247 \\
138 \\
163 \\
300\end{array}$ & $\begin{array}{l}26.8 \\
26.2 \\
28.1 \\
37.8 \\
69.3 \\
37.9\end{array}$ & $\begin{array}{l}240 \\
1092 \\
288\end{array}$ & $\begin{array}{l}5 \\
9 \\
3\end{array}$ & $\begin{array}{r}14 \\
527 \\
93\end{array}$ & $\begin{array}{l}147 \\
523 \\
129\end{array}$ & $\begin{array}{l}2.7 \\
9.8 \\
3.9\end{array}$ \\
\hline 30 & $\begin{array}{r}0-5 \\
5-10 \\
10-25 \\
15-19 \\
19-25\end{array}$ & $\begin{array}{l}30 \\
0 \\
21 \\
20 \\
60\end{array}$ & $\begin{array}{l}8.63 \\
6.76\end{array}$ & $\begin{array}{l}309 \\
304 \\
\text { Fur1 } \\
\text { ("8a1t } \\
\text { rum }\end{array}$ & $\begin{array}{l}\text { bs9 } \\
256 \\
\text { aret } \\
\text { aree } \\
\text { diet }\end{array}$ & $\left\{\begin{array}{l}369 \\
\text { a1et }\end{array}\right.$ & $\begin{array}{l}53.9 \\
53.2\end{array}$ & $\begin{array}{l}5.35 \\
4.90 \\
9.25 \\
9.50 \\
17.40\end{array}$ & $\begin{array}{l}262 \\
192 \\
377 \\
346 \\
870\end{array}$ & $\begin{array}{l}317 \\
162 \\
324 \\
319 \\
736\end{array}$ & $\begin{array}{l}139 \\
126 \\
365 \\
137 \\
197\end{array}$ & $\begin{array}{l}-2.1 \\
20.5 \\
0.5 \\
36.7 \\
53.6\end{array}$ & $\begin{array}{l}2466 \\
1443 \\
428 \\
317 \\
548\end{array}$ & $\begin{array}{r}13 \\
5 \\
1 \\
2 \\
21\end{array}$ & $\begin{array}{r}92 \\
18 \\
12 \\
8 \\
63\end{array}$ & $\begin{array}{c}94 \\
42 \\
122 \\
98 \\
230\end{array}$ & $\begin{array}{l}5.6 \\
4.8 \\
4.9 \\
3.8 \\
6.8\end{array}$ \\
\hline
\end{tabular}

ing calcium and phosphorus (Table XV and Figure 1). The chloride concentration, however, fell approximately 2 meq./1. in all patients without other change. Balance data, however, were not consistently altered in VB or JF (Table XVI).

\section{Comparison of the efficiency of the various resin forms}

Mean stool excretion of sodium and potassium per gram of resin was determined during administration of the hydrogen, ammonium, potassium, sodium, and calcium forms of the cation exchanger in the experiments in which sodium was not rigidly withheld. The few studies in which the diet was almost completely free of sodium are included in the tables, but excluded from the means, to illustrate the decrease in efficiency of the hydrogen and ammonium forms under such circumstances. For simplicity the calculations are omitted, but the findings can be summarized briefly.

The hydrogen, ammonium, and potassium forms of the resin removed equivalent amounts of sodium plus potassium in stools $(1.5,1.9$, and 1.9 meq./g. respectively). Mean stool sodium averaged 0.4 to 
TABLE IV

Intake data and urine and stool output in subjects receiving cation exchanger in the $\mathrm{NH}_{4}$ cycle

\begin{tabular}{|c|c|c|c|c|c|c|c|c|c|c|c|c|c|c|c|c|c|}
\hline \multirow[t]{2}{*}{ Subj. } & \multirow{2}{*}{$\frac{\text { Time }}{\text { (Days) }}$} & \multirow{2}{*}{$\begin{array}{c}\text { Therapy } \\
(g . / d .)\end{array}$} & \multicolumn{5}{|c|}{ Intake } & \multicolumn{5}{|c|}{ Urine } & \multicolumn{5}{|c|}{ Stool } \\
\hline & & & $\underset{(l .)}{\text { Fluid }}$ & $\underset{\text { (meq.) }}{\mathrm{Cl}}$ & $\underset{\text { (meq.) }}{\mathrm{Na}}$ & $\underset{\text { (meq.) }}{\mathbf{K}}$ & $\underset{(g .)}{N}$ & $\begin{array}{l}\text { Vol. } \\
(l .)\end{array}$ & $\underset{\text { (meq.) }}{\mathrm{Cl}}$ & $\underset{(\text { meq. })}{\mathrm{Na}}$ & $\underset{\text { (meq.) }}{\mathbf{K}}$ & $\begin{array}{l}\text { TN } \\
(\text { (g.) }\end{array}$ & $\underset{(\text { g.) }}{\text { Wgt. }}$ & $\underset{\text { (meq.) }}{\mathrm{Cl}}$ & $\underset{\text { (meq.) }}{\mathrm{Na}}$ & $\underset{\text { (meq.) }}{\mathbf{K}}$ & $\underset{(\boldsymbol{g} .)}{\mathbf{N}}$ \\
\hline \multirow[t]{3}{*}{ JF } & $0-6$ & 40 & \multicolumn{5}{|c|}{ Full diab. diet } & 17.60 & 1442 & 1045 & 396 & 90.6 & 73 & 0.3 & 10 & 25 & \\
\hline & $\begin{array}{r}6-12 \\
12-18\end{array}$ & $\begin{array}{r}0 \\
40\end{array}$ & $\begin{array}{l}23.23 \\
20.14\end{array}$ & \begin{tabular}{|l|}
521 \\
496
\end{tabular} & \begin{tabular}{|l|}
436 \\
416
\end{tabular} & $\begin{array}{l}622 \\
592\end{array}$ & $\begin{array}{l}90.6 \\
86.3\end{array}$ & $\begin{array}{r}12.15 \\
8.60\end{array}$ & $\begin{array}{l}401 \\
156\end{array}$ & $\begin{array}{r}343 \\
26\end{array}$ & $\begin{array}{l}274 \\
218\end{array}$ & $\begin{array}{l}75.6 \\
86.1\end{array}$ & $\begin{array}{l}286 \\
611\end{array}$ & $\begin{array}{l}0.3 \\
4\end{array}$ & $\begin{array}{l}30 \\
45\end{array}$ & $\begin{array}{l}122 \\
214\end{array}$ & $\begin{array}{l}2.6 \\
3.4\end{array}$ \\
\hline & $18-24$ & 0 & \multicolumn{5}{|c|}{ Full diab. diet } & 9.24 & 1850 & 1862 & 191 & 74.1 & 495 & 13 & 44 & 102 & 3.3 \\
\hline $\mathrm{CS}$ & $\begin{array}{l}0-6 \\
6-12\end{array}$ & $\begin{array}{r}40 \\
0\end{array}$ & \multicolumn{5}{|c|}{ Full diet } & $\begin{array}{l}7.00 \\
2.50\end{array}$ & $\begin{array}{l}735 \\
285\end{array}$ & $\begin{array}{l}367 \\
152\end{array}$ & $\begin{array}{r}189 \\
54\end{array}$ & $\begin{array}{l}46.6 \\
36.8\end{array}$ & $\begin{array}{l}704 \\
782\end{array}$ & $\begin{array}{l}18 \\
51\end{array}$ & $\begin{array}{r}398 \\
88\end{array}$ & $\begin{array}{r}130 \\
67\end{array}$ & 8.5 \\
\hline \multirow[t]{2}{*}{$\mathrm{CSc}$} & $0-7$ & 8 & 14.92 & 281 & 234 & 336 & 49.0 & \multirow{2}{*}{$\begin{array}{l}8.60 \\
8.10 \\
8.80\end{array}$} & \multirow{2}{*}{$\begin{array}{r}0 \\
26 \\
19\end{array}$} & \multirow{2}{*}{$\begin{array}{l}\mathbf{0} \\
\mathbf{3} \\
\mathbf{0}\end{array}$} & \multirow{2}{*}{$\begin{array}{r}305 \\
81 \\
62\end{array}$} & \multirow{2}{*}{$\frac{63.0}{41.9}$} & \multirow{2}{*}{$\begin{array}{l}- \\
910 \\
212\end{array}$} & \multirow{2}{*}{$\begin{array}{r}- \\
12 \\
3\end{array}$} & \multirow{2}{*}{$\begin{array}{r}- \\
48\end{array}$} & \multirow{2}{*}{$\begin{array}{r}- \\
240 \\
44\end{array}$} & \multirow{2}{*}{$\begin{array}{l}- \\
8.1 \\
1.9\end{array}$} \\
\hline & $\begin{array}{r}7-13 \\
13-19\end{array}$ & $\begin{array}{r}40 \\
0\end{array}$ & & "Sal & t-free" & diet & & & & & & & & & & & \\
\hline SB & $\begin{array}{c}0-3 \\
3-6 \\
6-9 \\
9-12 \\
12-15 \\
15-18 \\
18-21 \\
21-23\end{array}$ & $\begin{array}{l}40 \\
40 \\
40 \\
40 \\
40 \\
40 \\
40 \\
40\end{array}$ & \multicolumn{5}{|c|}{ Full diet } & $\begin{array}{l}4.00 \\
4.97 \\
4.13 \\
4.52 \\
4.26 \\
5.82 \\
4.66 \\
2.02\end{array}$ & $\begin{array}{r}408 \\
434 \\
369 \\
460 \\
466 \\
506 \\
301 \\
83\end{array}$ & $\begin{array}{l}185 \\
240 \\
224 \\
256 \\
318 \\
640 \\
-\end{array}$ & $\begin{array}{r}81 \\
55 \\
103 \\
39 \\
57 \\
54 \\
- \\
-\end{array}$ & $\begin{array}{c}40.3 \\
34.6 \\
- \\
33.1 \\
45.7 \\
46.0 \\
27.7 \\
-\end{array}$ & $\begin{array}{r}1228 \\
-\overline{1130} \\
642 \\
670 \\
259\end{array}$ & $\begin{array}{r}21 \\
13 \\
3 \\
3 \\
3\end{array}$ & $\begin{array}{r}181 \\
-293 \\
195 \\
192 \\
94\end{array}$ & $\begin{array}{r}266 \\
- \\
347 \\
162 \\
232 \\
50\end{array}$ & $\begin{array}{l}9.4 \\
8.4 \\
6.2 \\
6.9 \\
2.9\end{array}$ \\
\hline WY & $\begin{array}{l}0-6 \\
6-12\end{array}$ & $\begin{array}{r}40 \\
0\end{array}$ & $\begin{array}{l}11.89 \\
13.02\end{array}$ & $\begin{array}{l}261 \\
267\end{array}$ & $\begin{array}{l}219 \\
224\end{array}$ & $\begin{array}{l}311 \\
318\end{array}$ & $\begin{array}{l}45.4 \\
46.4\end{array}$ & $\begin{array}{l}6.40 \\
7.00\end{array}$ & $\begin{array}{r}95 \\
298\end{array}$ & $\begin{array}{r}85 \\
186\end{array}$ & $\begin{array}{l}160 \\
161\end{array}$ & $\begin{array}{l}41.4 \\
48.4\end{array}$ & $\begin{array}{r}2109 \\
850\end{array}$ & $\begin{array}{r}25 \\
3\end{array}$ & $\begin{array}{r}258 \\
17\end{array}$ & $\begin{array}{r}134 \\
80\end{array}$ & $\begin{array}{r}13.0 \\
8.0\end{array}$ \\
\hline EMc & $0-6$ & 40 & \multicolumn{5}{|c|}{ Full diab. diet } & & & & & & 346 & 1 & 118 & 166 & 2.4 \\
\hline \multirow[t]{2}{*}{ DY } & $0-4$ & 35 & \multicolumn{5}{|c|}{ Full diet } & 4.10 & 163 & 94 & 189 & $50.0 *$ & 570 & 3 & 123 & 132 & 5.7 \\
\hline & $4-10$ & 0 & 11.03 & 146 & 9 & 354 & 65.0 & 7.05 & 338 & 197 & 270 & $58.0 *$ & 1171 & 11 & 26 & 48 & 6.3 \\
\hline WG & $\begin{array}{c}0-5 \\
5-10 \\
10-15 \\
15-20 \\
20-26 \\
26-31\end{array}$ & $\begin{array}{r}0 \\
0 \\
0 \\
0 \\
38 \\
0\end{array}$ & $\begin{array}{l}12.64 \\
13.58 \\
13.80 \\
12.95 \\
16.72 \\
14.79\end{array}$ & $\begin{array}{l}223 \\
233 \\
233 \\
233 \\
251 \\
221\end{array}$ & $\begin{array}{l}13 \\
14 \\
14 \\
14 \\
15 \\
13\end{array}$ & $\begin{array}{l}542 \\
566 \\
566 \\
566 \\
608 \\
538\end{array}$ & $\begin{array}{r}64.0 \\
66.8 \\
66.8 \\
103.8 \\
111.6 \\
98.6\end{array}$ & $\begin{array}{r}7.88 \\
7.25 \\
9.19 \\
7.72 \\
12.15 \\
6.24\end{array}$ & $\begin{array}{l}386 \\
251 \\
275 \\
268 \\
359 \\
204\end{array}$ & $\begin{array}{r}272 \\
54 \\
21 \\
68 \\
85 \\
67\end{array}$ & $\begin{array}{l}259 \\
338 \\
391 \\
363 \\
101 \\
106\end{array}$ & $\begin{array}{l}40.1 \\
48.9 \\
52.7 \\
56.4 \\
96.6 \\
57.7\end{array}$ & $\begin{array}{l}470 \\
299 \\
534 \\
475 \\
766 \\
782\end{array}$ & $\begin{array}{l}5 \\
3 \\
6 \\
5 \\
6 \\
5\end{array}$ & $\begin{array}{r}6 \\
9 \\
3 \\
8 \\
28 \\
31\end{array}$ & $\begin{array}{r}96 \\
51 \\
90 \\
77 \\
240 \\
288\end{array}$ & $\begin{array}{l}5.2 \\
3.7 \\
5.9 \\
6.8 \\
6.7 \\
7.2\end{array}$ \\
\hline
\end{tabular}

* TN values in this patient include 37.4 and 45.3 g., respectively, of NPN.

1.0 meq./g. for each of these forms. All of these exchangers were more effective in this respect than the calcium cycle. With regard to potassium the hydrogen, ammonium and sodium forms proved to be equally effective in augmenting the loss of this electrolyte via the gastrointestinal tract. They were again superior to the calcium form. More potassium was excreted in the stool during potassium cycle resin administration than during the ingestion of any other form of the exchanger. It does not seem likely that this represents increased removal of endogenous or dietary potassium, since the amounts of this cation recovered in the stools were less than that administered in the resin. The large amount of potassium found in the stool would appear to be best explained by "unchanged resin" or the temporary release of potassium in the acid medium of the stomach and subsequent recovery of large amounts of the cation in the alkaline small intestine by the exchanger. The same reasoning regarding sodium may be applied to the sodium form of the carboxylic resin. Each gram of the potassium and sodium forms of the resin contained 3.8 meq. of their respective cations prior to administration.

\section{E. Clinical concomitants of resin therapy}

Ambulatory patients or those without discomfort tolerated the above cation exchangers quite well, whereas those with gastrointestinal symptoms or general malaise experienced varying degrees of difficulty in ingesting and retaining the larger 
dosage. In some, emesis was extensive enough to prevent administration of the exchangers; these subjects have been excluded from our studies.

Seven of the studies with the hydrogen or ammonium forms of the resin were conducted in patients with diabetes mellitus. Though the carbohydrate data have been omitted for purposes of brevity the results indicated that the development of acidosis as a result of resin ingestion was not accompanied by ketone bodies in the urine and did not exert any visibly deleterious effect on car-
TABLE V

Statistical expression of urine data during $H$ resin therapy

\begin{tabular}{|c|c|c|c|c|c|c|c|c|}
\hline & \multicolumn{3}{|c|}{$\begin{array}{l}\text { Control and } \\
\text { post resin* }\end{array}$} & \multicolumn{5}{|c|}{ Resin } \\
\hline & Mean & No. & S. D. & Mean & No. & S. D. & " $t "$ & "p" \\
\hline $\begin{array}{l}\text { Volume }(m l .) \\
\mathrm{Cl}(\text { meq. } / d .) \\
\mathrm{Na}(\text { meq. } / d .) \\
\mathrm{K}(\text { meq. } / d .) \\
\mathrm{TN}\left(\mathrm{g}_{.} / d .\right)\end{array}$ & $\begin{array}{r}1026.1 \\
89.5 \\
78.9 \\
39.5 \\
8.0\end{array}$ & \begin{tabular}{|l|}
20 \\
21 \\
21 \\
21 \\
21
\end{tabular} & \begin{tabular}{|r|}
531.2 \\
54.3 \\
63.2 \\
23.1 \\
3.1
\end{tabular} & $\begin{array}{c}1873.9>t \\
104.4 \\
67.9 \\
35.8 \\
9.2\end{array}$ & $\begin{array}{l}22 \\
21 \\
20 \\
21 \\
21\end{array}$ & \begin{tabular}{|r|}
75.9 \\
54.6 \\
45.6 \\
19.2 \\
2.6
\end{tabular} & $\begin{array}{l}3.99+ \\
0.89 \\
0.62 \\
0.55 \\
1.25\end{array}$ & $\begin{array}{l}0.0025 \\
0.38 \\
0.52 \\
0.62 \\
0.22\end{array}$ \\
\hline
\end{tabular}

- Control and post resin periods combined after statistical demonstration that they were indistinguishable.

† Significantly greater than controls

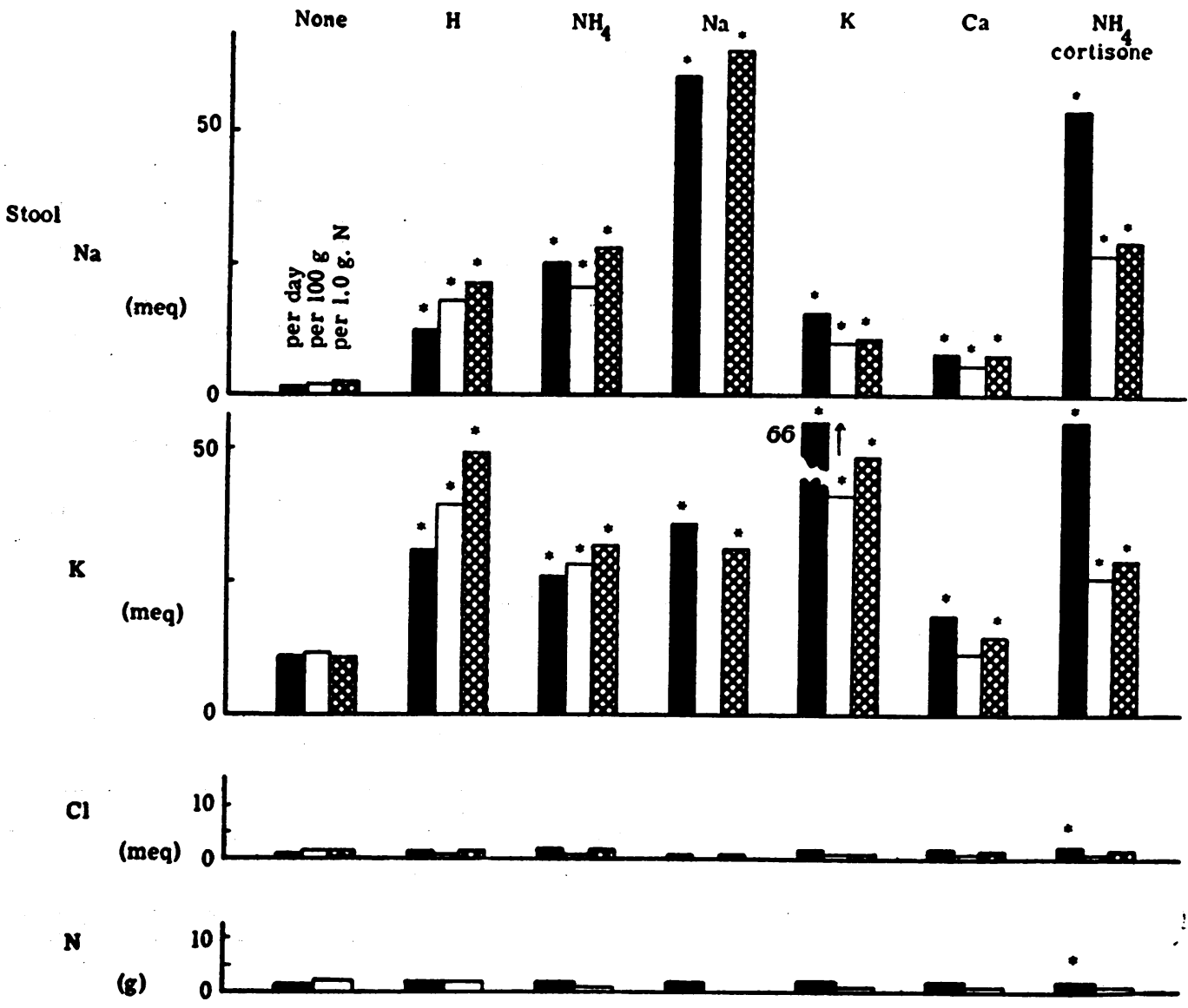

Fig. 2. Stool DAta

The columns represent stool excretion of $\mathrm{Na}, \mathrm{K}, \mathrm{Cl}$, and $\mathrm{N}$ per day, per $100 \mathrm{~g}$. of wet stool, and per $1.0 \mathrm{~g}$. of nitrogen during therapy indicated at the head of each group of columns. Again the chemical abbreviations indicate the form of the resin ingested, and the asterisks stand for values significantly different from the control column entitled "none." The column headed "NH4 cortisone" indicates the patient receiving the $\mathrm{NH}_{4}$ form of the resin together with cortisone. Stool excretion of sodium and of potassium increased to a variable degree irrespective of the particular form of the resin administered, or of cortisone therapy. Mean stool chloride and nitrogen values were not changed during the ingestion of any of the exchangers, but did increase slightly when cortisone was given during $\mathrm{NH}_{4}$ form therapy in one patient. 
TABLE VI

External, extracellular, and cell balances in subjects receiving the cation exchanger in the $H$ cycle

\begin{tabular}{|c|c|c|c|c|c|c|c|c|c|c|c|c|c|}
\hline Subject & IIIme & Therapy & & Ext. & 1. & & & coell. & & & $.212 \mathrm{Bal}$ & & \\
\hline & (Days) & $\left(c_{\cdot} / d_{.}\right)$ & $\begin{array}{c}C 1 \\
\text { (aneg.) }\end{array}$ & $\left(\begin{array}{c}M_{0} \\
(\operatorname{mog} .)\end{array}\right.$ & 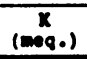 & (En.) & (1.) & $\left.\cos _{(\mathbf{m e q}}\right)$ & $\begin{array}{c}x \\
(\mathbf{m} 09 .)\end{array}$ & $\left(m_{m}^{n}\right)$ & $\ln _{(=0,0)}$ & $\underset{(\operatorname{mog} .)}{x}$ & $\lim _{\operatorname{lin}}$ \\
\hline$w$ & $\begin{array}{r}0-3 \\
3-6 \\
6-9 \\
9-12 \\
\end{array}$ & $\begin{array}{r}0 \\
0 \\
25 \\
35\end{array}$ & $\begin{array}{r}+31 \\
+\quad 94 \\
+\quad 77 \\
+\quad 25 \\
\end{array}$ & $\begin{array}{r}31 \\
+\quad 59 \\
+\quad 30 \\
+\quad 27 \\
\end{array}$ & $\begin{array}{r}-21 \\
+11 \\
-92 \\
+\quad 1 \\
\end{array}$ & $\begin{array}{r}2.7 \\
+6.0 \\
+\quad 9.1 \\
+5.3 \\
\end{array}$ & $\begin{array}{l}+0.5 \\
+0.1 \\
+0.6 \\
+0.3 \\
\end{array}$ & $\begin{array}{r}+101 \\
+29 \\
+\quad 85 \\
+\quad 12 \\
\end{array}$ & $\begin{array}{r}+4 \\
+4 \\
+2 \\
+5 \\
\end{array}$ & $\begin{array}{r}2.7 \\
+6.4 \\
+8.9 \\
+\quad 5.5 \\
\end{array}$ & $\begin{array}{r}70 \\
+\quad 30 \\
-\quad 55 \\
+\quad 15 \\
\end{array}$ & $\begin{array}{r}-25 \\
+15 \\
-94 \\
+\quad 2 \\
\end{array}$ & $\begin{array}{r}31 \\
0 \\
-115 \\
-\quad 12 \\
\end{array}$ \\
\hline cas & $\begin{array}{r}0-3 \\
3-6 \\
6-9 \\
2-12 \\
\end{array}$ & $\begin{array}{r}0 \\
0 \\
25 \\
35\end{array}$ & $\begin{array}{r}+62 \\
+133 \\
+175 \\
+55 \\
\end{array}$ & $\begin{array}{r}6 \\
+\quad 48 \\
+180 \\
+\quad 37 \\
\end{array}$ & $\begin{array}{r}55 \\
+64 \\
+81 \\
0197 \\
\end{array}$ & $\begin{array}{r}+7.9 \\
+10.2 \\
+12.6 \\
+7.0 \\
\end{array}$ & $\begin{array}{r}+0.6 \\
+1.0 \\
+1.1 \\
+0.3 \\
\end{array}$ & $\begin{array}{r}+79 \\
+182 \\
+124 \\
+26 \\
\end{array}$ & $\begin{array}{r}+5 \\
+4 \\
+20 \\
-12 \\
\end{array}$ & $\begin{array}{r}9.0 \\
+9.4 \\
+13.4 \\
+6.7 \\
\end{array}$ & $\begin{array}{r}-73 \\
-134 \\
+56 \\
+11 \\
\end{array}$ & $\begin{array}{r}50 \\
+68 \\
+61 \\
+29 \\
\end{array}$ & $\begin{array}{r}+29 \\
+\quad 46 \\
+29 \\
+103 \\
\end{array}$ \\
\hline vo & $\begin{array}{r}0-3 \\
3-6 \\
6-9 \\
9-12 \\
12-15 \\
15-18 \\
18-21 \\
21-24 \\
24-21\end{array}$ & $\begin{array}{r}0 \\
0 \\
0 \\
32 \\
32 \\
32 \\
0 \\
0 \\
0 \\
\end{array}$ & $\begin{array}{r}+28 \\
+132 \\
-\quad 20 \\
-\quad 1 \\
-17 \\
-303 \\
-177 \\
-\quad 68 \\
-\quad 5 \\
\end{array}$ & $\begin{array}{r}-7 \\
+66 \\
-91 \\
-46 \\
+76 \\
-19 \\
-107 \\
-46 \\
-66 \\
\end{array}$ & $\begin{array}{r}+50 \\
+74 \\
+24 \\
-28 \\
+13 \\
+26 \\
+83 \\
+80 \\
+\quad 46 \\
\end{array}$ & $\begin{array}{r}-1.9 \\
+10.3 \\
+0.4 \\
-0.1 \\
-0.6 \\
+6.7 \\
-2.5 \\
-8.2 \\
-2.1 \\
\end{array}$ & $\begin{array}{l}+0.1 \\
+2.1 \\
+0.2 \\
-1.8 \\
-1.0 \\
-1.9 \\
-0.3 \\
-0.1 \\
+0.6 \\
\end{array}$ & $\begin{array}{r}+272 \\
-116 \\
-65 \\
-366 \\
+36 \\
-318 \\
+104 \\
-80 \\
+117 \\
\end{array}$ & $\begin{array}{r}+9 \\
+5 \\
+1 \\
-2 \\
-13 \\
-16 \\
+9 \\
+13 \\
-21 \\
\end{array}$ & $\begin{array}{r}-4.7 \\
+15.0 \\
+3.2 \\
-0.1 \\
-1.5 \\
+6.7 \\
-4.8 \\
-4.5 \\
-4.8 \\
\end{array}$ & $\begin{array}{r}-279 \\
+182 \\
-26 \\
+320 \\
+40 \\
+299 \\
-211 \\
+34 \\
-183 \\
\end{array}$ & $\begin{array}{r}+41 \\
+79 \\
-15 \\
-26 \\
+26 \\
+44 \\
+74 \\
+27 \\
+67 \\
\end{array}$ & $\begin{array}{r}+52 \\
+43 \\
-\quad 23 \\
-26 \\
+\quad 30 \\
+26 \\
+97 \\
+40 \\
+78 \\
\end{array}$ \\
\hline wx & $\begin{array}{r}0-2 \\
2-4 \\
6-6 \\
6-8 \\
8-9 \\
9-13 \\
23-15\end{array}$ & $\begin{array}{l}32 \\
32 \\
32 \\
32 \\
32 \\
32 \\
0 \\
0 \\
\end{array}$ & $\begin{array}{r}-53 \\
-105 \\
-12 \\
-20 \\
+2 \\
+22 \\
+72 \\
\end{array}$ & $\begin{array}{r}-100 \\
-123 \\
-48 \\
-44 \\
-15 \\
-48 \\
-\quad 5 \\
\end{array}$ & $\begin{array}{r}83 \\
+80 \\
+133 \\
+118 \\
+83 \\
+354 \\
+204 \\
\end{array}$ & $\begin{array}{r}8.3 \\
+6.0 \\
+7.2 \\
+0.9 \\
3.3 \\
+2.6 \\
+18.7\end{array}$ & $\begin{array}{l}-1.2 \\
-0.9 \\
+0.1 \\
-0.2 \\
-0.3 \\
+0.7 \\
+0.6\end{array}$ & $\begin{array}{r}-198 \\
-145 \\
+51 \\
-16 \\
-41 \\
+113 \\
+64 \\
\end{array}$ & $\begin{array}{r}-8 \\
-12 \\
+5 \\
+3 \\
-6 \\
+5 \\
+2\end{array}$ & $\begin{array}{r}4.6 \\
+5.2 \\
+8.4 \\
+0.9 \\
44.0 \\
+2.2 \\
+19.8 \\
\end{array}$ & $\begin{array}{r}+98 \\
+22 \\
-99 \\
-28 \\
+26 \\
-162 \\
-69 \\
\end{array}$ & $\begin{array}{r}+91 \\
+102 \\
+128 \\
+115 \\
+89 \\
+349 \\
+195\end{array}$ & $\begin{array}{r}80 \\
+90 \\
+108 \\
+113 \\
+79 \\
+344 \\
+148\end{array}$ \\
\hline $\csc$ & $\begin{array}{r}0-3 \\
3-6 \\
6-9 \\
9-12 \\
12-15 \\
15-19\end{array}$ & $\begin{array}{c}0 \\
0 \\
32 \\
32 \\
0 \\
0 \\
\end{array}$ & $\begin{array}{r}+105 \\
+219 \\
-90 \\
+54 \\
-139 \\
-89 \\
\end{array}$ & $\begin{array}{r}+245 \\
+150 \\
-349 \\
-149 \\
-106 \\
-86 \\
\end{array}$ & $\begin{array}{r}-29 \\
-23 \\
-254 \\
-106 \\
+44 \\
+40\end{array}$ & $\begin{array}{l}5.1 \\
+9.5 \\
+4.0 \\
-0.3 \\
+0.5 \\
+7.5\end{array}$ & $\begin{array}{l}+1.4 \\
+1.1 \\
-1.2 \\
+0.6 \\
-0.8 \\
-0.8 \\
\end{array}$ & $\begin{array}{l}+147 \\
+237 \\
-205 \\
+103 \\
-139 \\
-94 \\
\end{array}$ & $\begin{array}{r}+6 \\
+2 \\
-9 \\
-1 \\
+7 \\
-1 \\
\end{array}$ & $\begin{array}{r}5.4 \\
+9.8 \\
+4.7 \\
-0.3 \\
-0.1 \\
+1.5\end{array}$ & $\begin{array}{r}198 \\
-85 \\
-144 \\
-252 \\
-\quad 37 \\
+\quad 6 \\
\end{array}$ & $\begin{array}{r}-35 \\
-25 \\
-245 \\
-105 \\
-37 \\
+41 \\
\end{array}$ & $\begin{array}{r}-48 \\
-48 \\
-256 \\
-104 \\
-37 \\
-23 \\
\end{array}$ \\
\hline CDe & $\begin{array}{r}0-5 \\
5-10\end{array}$ & $\begin{array}{r}30 \\
0\end{array}$ & $\begin{array}{r}32 \\
+200\end{array}$ & $\begin{array}{r}-153 \\
+83\end{array}$ & $\begin{array}{r}+136 \\
295\end{array}$ & $\begin{array}{r}+25.9 \\
+25.5\end{array}$ & $\begin{array}{l}-1.3 \\
+1.3\end{array}$ & $\begin{array}{r}-249 \\
+123\end{array}$ & $\begin{array}{l}+15 \\
-21\end{array}$ & $\begin{array}{r}+23.3 \\
+28.1\end{array}$ & $\begin{array}{r}96 \\
+206\end{array}$ & $\begin{array}{r}+122 \\
+206\end{array}$ & 1.65 \\
\hline
\end{tabular}

* Value has been corrected for external balances of NPN

** $\mathrm{K}$ represents transfers of $\mathrm{K}$ in excess of protein metabolism

TABLE VII

External, extracellular, and cell balances in subjects receiving the cation exchanger in the $\mathrm{NH}_{4}$ cycle

\begin{tabular}{|c|c|c|c|c|c|c|c|c|c|c|c|c|c|}
\hline subject & Time & Thereps & & Ext. & a. & & & acell. & & & $012 \mathrm{Bal}$ & & \\
\hline & (nom) & (nalen) & $\left.{ }_{(\cos }{ }^{21}\right)$ & $\left(\begin{array}{l}n 0 \\
(m, 1)\end{array}\right.$ & $\left(\begin{array}{l}x \\
(-0)\end{array}\right.$ & (2.). & $\begin{array}{l}4.0 \\
12.1\end{array}$ & $\left(\ln _{0.9}\right)$ & $\begin{array}{c}\pi \\
(\operatorname{mog} .)\end{array}$ & $\left(m_{0}\right)$ & $\left(\lim _{0}\right)$ & $\begin{array}{c}R \\
(\operatorname{mog} .)\end{array}$ & $x \rightarrow$ \\
\hline $\boldsymbol{x}$ & $\begin{array}{r}6-12 \\
23-18 \\
\end{array}$ & 10 & $\begin{array}{r}+217 \\
+332 \\
\end{array}$ & $\begin{array}{r}59 \\
+29 \\
\end{array}$ & $\begin{array}{r}+226 \\
+160 \\
\end{array}$ & $\begin{array}{r}+12.1 \\
-3.5 \\
\end{array}$ & $\begin{array}{r}+1.3 \\
12.8\end{array}$ & $\begin{array}{r}+195 \\
+2006 \\
\end{array}$ & $\begin{array}{r}+6 \\
+22 \\
\end{array}$ & $\begin{array}{r}+9.0 \\
-2.2 \\
\end{array}$ & $\begin{array}{r}-236 \\
+134 \\
\end{array}$ & $\begin{array}{r}+220 \\
+138 \\
\end{array}$ & $\begin{array}{r}419 \\
614 \\
\end{array}$ \\
\hline C:S & 02 & 3 & 190 & se30 & +31 & $-24,3$ & 11.9 & 183 & -12 & -14.6 & -13 & +43 & \\
\hline$m$ & $\begin{array}{r}0-6 \\
6-12 \\
\end{array}$ & $\begin{array}{l}10 \\
0\end{array}$ & $\begin{array}{r}+139 \\
-\quad 36 \\
\end{array}$ & $\begin{array}{r}-128 \\
+17 \\
\end{array}$ & & $\begin{array}{r}-9.3 \\
-910.3\end{array}$ & $\begin{array}{l}11.0 \\
-0.3 \\
\end{array}$ & $\begin{array}{r}+231 \\
-103 \\
\end{array}$ & $\begin{array}{r}-15 \\
+1 .\end{array}$ & $\begin{array}{r}-6.9 \\
-6.6 \\
\end{array}$ & $\begin{array}{r}-359 \\
+190 \\
\end{array}$ & $\begin{array}{r}32 \\
-69 \\
\end{array}$ & \\
\hline$x$ & +20 & 0 & . & -217 & 26 & +0.5 & -2.4 & -201 & +4 & -0.2 & -16 & +39 & \\
\hline$\omega$ & $\begin{array}{r}0-5 \\
5-10 \\
10-15 \\
15-20 \\
20-26 \\
26-31\end{array}$ & $\begin{array}{r}0 \\
0 \\
0 \\
0 \\
38 \\
0\end{array}$ & $\begin{array}{l}-27 \\
-24 \\
=51 \\
-542 \\
-217 \\
+12\end{array}$ & $\begin{array}{l}-269 \\
-58 \\
=23 \\
-65 \\
-201 \\
-89\end{array}$ & $\begin{array}{r}+188 \\
+177 \\
+86 \\
+126 \\
+267 \\
+114\end{array}$ & $\begin{array}{r}+28.4 \\
+23.9 \\
+7.9 \\
+40.3 \\
+8.0 \\
+23.4\end{array}$ & $\begin{array}{l}-1.8 \\
+0.6 \\
-0.6 \\
-0.7 \\
-1.0 \\
+0.3\end{array}$ & $\begin{array}{l}-206 \\
+100 \\
-110 \\
-84 \\
-135 \\
+80\end{array}$ & $\begin{array}{r}-6 \\
+5 \\
0 \\
-21 \\
-8 \\
+3\end{array}$ & $\begin{array}{r}+16.7 \\
+15.5 \\
+7.7 \\
+40.5 \\
+7.6 \\
+89.0\end{array}$ & $\begin{array}{r}-63 \\
-250 \\
+97 \\
-19 \\
+37 \\
-190\end{array}$ & $\begin{array}{r}+294 \\
+172 \\
+86 \\
+137 \\
+275 \\
829\end{array}$ & 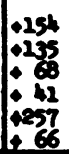 \\
\hline
\end{tabular}

* Value has been corrected for external balance of NPN

** $\mathrm{K}$ represents transfers of $\mathrm{K}$ in excess of protein metabolism 
TABLE VIII

Body weight and analyses of blood and serum in subjects receiving the cation exchanger in the Na cycle

\begin{tabular}{|c|c|c|c|c|c|c|c|c|c|c|c|c|c|}
\hline \multirow{2}{*}{$\frac{\text { Subject }}{\text { (Age-Sex) }}$} & \multirow{2}{*}{$\frac{\text { Tine }}{\text { (Dave) }}$} & \multirow{2}{*}{$\frac{\text { Therapy }}{\left(\mathrm{c} \cdot / \mathrm{d}_{\text {. }}\right)}$} & \multirow{2}{*}{$\frac{\text { Body wet. }}{(\mathrm{kg} \cdot)}$} & \multicolumn{2}{|c|}{ Blood } & \multicolumn{8}{|c|}{ Serun } \\
\hline & & & & $\begin{array}{c}\text { Sugar } \\
(\text { menos) }\end{array}$ & $\underset{(m, N)}{M}$ & $\begin{array}{r}\mathrm{HCO} \\
\text { (meq./2.) }\end{array}$ & $\begin{array}{c}C l \\
(m e q . / 1 .)\end{array}$ & $\begin{array}{c}M a \\
(m e q . / 1 .)\end{array}$ & $\begin{array}{c}\mathrm{K} \\
(\text { meq./1.) }\end{array}$ & $\begin{array}{c}\mathrm{Ca} \\
\text { (mesons) }\end{array}$ & $\begin{array}{c}P \\
(\operatorname{mog} x)\end{array}$ & $\begin{array}{c}H, 0 \\
(8 . / 1.0)\end{array}$ & $\begin{array}{c}\text { Protein } \\
(c . x)\end{array}$ \\
\hline $\begin{array}{l}\text { 20: } \\
14 x \\
\text { Diab. }\end{array}$ & $\begin{array}{r}0 \\
0-3 \\
3-6 \\
6-7 \\
7-10 \\
10-13 \\
\end{array}$ & $\begin{array}{r}0 \\
0 \\
0 \\
0 \\
40 \\
40 \\
\end{array}$ & $\begin{array}{l}51.0 \\
50.8 \\
51.0 \\
51.4 \\
51.8 \\
51.8\end{array}$ & $\begin{array}{c}172 \\
240 \\
273 \\
- \\
226 \\
- \\
\end{array}$ & $\begin{array}{l}31 \\
34 \\
33 \\
38 \\
33 \\
33 \\
\end{array}$ & $\begin{array}{l}23.9 \\
24.8 \\
25.4 \\
26.2 \\
27.0 \\
23.6\end{array}$ & $\begin{array}{r}99.4 \\
99.5 \\
100.8 \\
104.7 \\
101.0 \\
102.1 \\
\end{array}$ & $\begin{array}{l}140 \\
149 \\
144 \\
142 \\
138 \\
143\end{array}$ & $\begin{array}{l}4.3 \\
4.6 \\
5.3 \\
4.2 \\
4.3 \\
4.6 \\
\end{array}$ & $\begin{array}{c}10.3 \\
- \\
9.8 \\
10.2 \\
- \\
-\end{array}$ & $\begin{array}{l}5.0 \\
5.0 \\
4.6 \\
4.7 \\
\end{array}$ & $\begin{array}{c}937 \\
- \\
932 \\
936\end{array}$ & $\begin{array}{l}6.7 \\
7.2 \\
7.6 \\
6.8 \\
\end{array}$ \\
\hline $\begin{array}{l}\text { N } \\
15 \mathrm{M} \\
\text { D1ab. }\end{array}$ & $\begin{array}{r}0 \\
0-3 \\
3-6 \\
6-7 \\
7-10 \\
10-13 \\
\end{array}$ & $\begin{array}{r}0 \\
0 \\
0 \\
0 \\
40 \\
40 \\
\end{array}$ & $\begin{array}{l}54.2 \\
54.4 \\
54.6 \\
54.0 \\
55.4 \\
55.4 \\
\end{array}$ & $\begin{array}{c}173 \\
318 \\
249 \\
- \\
222 \\
- \\
\end{array}$ & $\begin{array}{l}32 \\
36 \\
33 \\
35 \\
33 \\
34 \\
\end{array}$ & $\begin{array}{l}25.7 \\
25.4 \\
25.9 \\
26.3 \\
27.2 \\
25.3 \\
\end{array}$ & $\begin{array}{l}96.7 \\
97.7 \\
98.7 \\
98.7 \\
98.9 \\
99.1 \\
\end{array}$ & $\begin{array}{l}139 \\
147 \\
142 \\
0 \\
142 \\
143\end{array}$ & $\begin{array}{l}3.8 \\
4.5 \\
4.3 \\
5.3 \\
4.3 \\
4.8 \\
\end{array}$ & $\begin{array}{c}10.2 \\
10.0 \\
10.2 \\
- \\
\end{array}$ & $\begin{array}{l}3.8 \\
4.1 \\
4.6 \\
4.0 \\
\end{array}$ & $\begin{array}{c}932 \\
930 \\
- \\
928\end{array}$ & $\begin{array}{l}6.5 \\
6.8 \\
7.0 \\
6.7\end{array}$ \\
\hline $\begin{array}{l}\text { VB } \\
\text { il } M \\
\text { Rh. Per. }\end{array}$ & $\begin{array}{r}0 \\
0-8\end{array}$ & 40 & $\begin{array}{l}36.6 \\
37.4\end{array}$ & $\begin{array}{l}75 \\
91\end{array}$ & $\begin{array}{l}35 \\
30\end{array}$ & $\begin{array}{l}24.0 \\
26.0\end{array}$ & $\begin{array}{r}100.0 \\
97.4\end{array}$ & $\begin{array}{l}139 . \\
144 .\end{array}$ & 3.5 & - & $\begin{array}{l}4.9 \\
4.9\end{array}$ & $\begin{array}{l}923 \\
931\end{array}$ & $\begin{array}{l}8.0 \\
7.3\end{array}$ \\
\hline
\end{tabular}

* End of $\mathrm{Ca}$ cycle resin

TABLE IX

Body weight and analyses of blood and serum in subjects receiving cation exchanger in the $K$ cycle

\begin{tabular}{|c|c|c|c|c|c|c|c|c|c|c|c|c|c|}
\hline subjeet & ring & Jworapy & Body Wret. & \multicolumn{2}{|c|}{ Blood } & \multicolumn{8}{|c|}{ Serun } \\
\hline (1)e-sex) & (Days) & $\left(g_{0} / d_{0}\right)$ & (ks) & $\begin{array}{l}\text { Sugar } \\
\text { (acus ) }\end{array}$ & $\begin{array}{c}N P N_{1} \\
(n g m)\end{array}$ & $\begin{array}{c}\mathrm{HCO}, \\
(\mathrm{meg} \cdot \mathrm{M} .)\end{array}$ & \begin{tabular}{c|c|}
$C 1$ \\
(neg./1.)
\end{tabular} & $\begin{array}{c}N_{a} \\
(\text { neq./1.) }\end{array}$ & $\begin{array}{c}\mathrm{X} \\
(\text { meq./12.) }\end{array}$ & ${ }_{(m, x)}^{C e}$ & $\left(\begin{array}{l}P \\
(n+\infty)\end{array}\right.$ & $\begin{array}{c}H, 0 \\
(c . / 1 .)\end{array}$ & $\begin{array}{c}\text { Proteln } \\
(6.8)\end{array}$ \\
\hline $\begin{array}{l}\text { nc } \\
13 n \\
\text { Disurtes }\end{array}$ & $\begin{array}{r}0 \\
0-4 \\
46 \\
6-9 \\
9-12\end{array}$ & $\begin{array}{l}0 \\
60 \\
60 \\
60 \\
60 \\
\end{array}$ & $\begin{array}{l}48.4 \\
47.4 \\
47.2 \\
48.0 \\
48.8\end{array}$ & $\begin{array}{c}- \\
- \\
311 \\
286 \\
288\end{array}$ & $\begin{array}{l}32 \\
37 \\
35 \\
33 \\
33\end{array}$ & $\begin{array}{l}24.4 \\
22.7 \\
25.1 \\
23.3 \\
25.0\end{array}$ & $\begin{array}{r}91.0 \\
100.7 \\
99.7 \\
99.4 \\
101.0\end{array}$ & $\begin{array}{l}150 \\
140 \\
142 \\
143 \\
148\end{array}$ & $\begin{array}{l}5.2 \\
4.2 \\
4.2 \\
4.5 \\
4.6\end{array}$ & $\begin{array}{c}10.0 \\
- \\
10.0 \\
9.1 \\
9.1\end{array}$ & $\begin{array}{r}3.8 \\
- \\
4.4 \\
4.5 \\
4.1\end{array}$ & $\begin{array}{l}- \\
934 \\
936 \\
931 \\
931\end{array}$ & $\begin{array}{c}- \\
7.0 \\
6.8 \\
-\end{array}$ \\
\hline 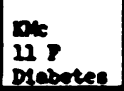 & $\begin{array}{c}\infty \\
0-3\end{array}$ & 10 & - & $\begin{array}{l}209 \\
255\end{array}$ & $\begin{array}{l}34 \\
32\end{array}$ & $\begin{array}{l}16.9 \\
27.3\end{array}$ & $\begin{array}{l}109.2 \\
101.4\end{array}$ & $\begin{array}{l}143 \\
137\end{array}$ & $\begin{array}{l}3.7 \\
4.2\end{array}$ & 9.6 & 4.5 & $\begin{array}{l}929 \\
935\end{array}$ & 7.9 \\
\hline $\begin{array}{l}\text { Cot } \\
\text { St } n \\
\text { Artmites }\end{array}$ & $\begin{array}{r}0 \\
0-6 \\
6-22 \\
\end{array}$ & $\begin{array}{r}0 \\
40 \\
0 \\
\end{array}$ & $\begin{array}{c}60.2 \\
. \\
- \\
\end{array}$ & - & $\begin{array}{l}31 \\
34 n \\
35\end{array}$ & $\begin{array}{l}27.6 \\
28.7 \\
26.0 \\
\end{array}$ & $\begin{array}{l}101.7 \\
100.5 \\
106.1 \\
\end{array}$ & $\begin{array}{l}145 \\
145 \\
147\end{array}$ & $\begin{array}{l}4.4 \\
6.1 \\
4.0 \\
\end{array}$ & $\begin{array}{l}8.9 \\
8.8 \\
9.2 \\
\end{array}$ & $\begin{array}{l}2.1 \\
2.9 \\
2.7\end{array}$ & $\begin{array}{l}938 \\
936 \\
930\end{array}$ & $\begin{array}{l}- \\
6.7 \\
7.0\end{array}$ \\
\hline 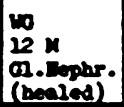 & $\underset{5-10}{0-5}$ & $\begin{array}{r}0 \\
0\end{array}$ & $\begin{array}{l}30.0 \\
29.8 \\
29.8\end{array}$ & $\ddot{-}$ & $\begin{array}{l}37 \\
40\end{array}$ & $\begin{array}{l}26.6 \\
26.6 \\
28.1\end{array}$ & $\begin{array}{r}105.0 \\
101.5 \\
99.6\end{array}$ & $\begin{array}{l}141 \\
137 \\
145\end{array}$ & $\begin{array}{l}3.8 \\
4.0 \\
4.4\end{array}$ & $\begin{array}{l}- \\
10.0 \\
10.1\end{array}$ & $\begin{array}{l}- \\
5.6 \\
5.5\end{array}$ & ses & $\begin{array}{l}- \\
7.8 \\
8.2\end{array}$ \\
\hline $\begin{array}{l}\csc \\
33{ }^{2} \\
c-7 \text { an. }\end{array}$ & $\begin{array}{r}0 \\
0.5\end{array}$ & 32 & $\begin{array}{l}47.5 \\
48.7\end{array}$ & - & $\begin{array}{l}39 \\
38\end{array}$ & $\begin{array}{l}28.9 \\
29.4\end{array}$ & $\begin{array}{l}86.7 \\
90.8\end{array}$ & $\begin{array}{l}137 \\
142\end{array}$ & $\begin{array}{l}4.3 \\
6.1\end{array}$ & $\begin{array}{l}8.8 \\
8.8\end{array}$ & $\begin{array}{l}4.1 \\
5.0\end{array}$ & 939 & $\begin{array}{l}6.6 \\
6.3\end{array}$ \\
\hline
\end{tabular}

* End of $\mathrm{H}$ cycle resin

\# Drawn on seventh day

** End of $\mathrm{NH}_{4}$ cycle

TABLE $\mathbf{X}$

Intake data and urine and stool output in subjects receiving the cation exchanger in the Na cycle

\begin{tabular}{|c|c|c|c|c|c|c|c|c|c|c|c|c|c|c|c|c|c|}
\hline \multirow[t]{2}{*}{ subs. } & \multirow{2}{*}{$\begin{array}{c}\text { Ildo } \\
\text { (days) }\end{array}$} & \multirow{2}{*}{$\begin{array}{l}\text { Therapy } \\
\left(\mathrm{g} \cdot / \mathrm{d}_{\text {. }}\right)\end{array}$} & \multicolumn{5}{|c|}{ Intake } & \multicolumn{5}{|c|}{ Urine } & \multicolumn{5}{|c|}{ St00l } \\
\hline & & & $\begin{array}{c}\text { Fluid } \\
(1 .)\end{array}$ & $\begin{array}{c}\mathrm{Cl} \\
(\mathrm{meq})\end{array}$ & $\begin{array}{c}\mathrm{Ma} \\
(\text { mog. })\end{array}$ & $\begin{array}{c}K \\
(m e q .)\end{array}$ & $(\sin )$ & $\begin{array}{l}\text { Vol. } \\
\text { (2.) }\end{array}$ & $\begin{array}{c}\mathrm{Cl} \\
(\text { meq. })\end{array}$ & $\begin{array}{c}\mathrm{Na} \\
(\mathrm{meq}) \\
\end{array}$ & $\begin{array}{c}K \\
(m \in d .)\end{array}$ & $\begin{array}{c}T N \\
\left(g^{m} .\right)\end{array}$ & $\begin{array}{l}\text { mgti } \\
\left(g^{2}\right)\end{array}$ & $\begin{array}{c}\mathrm{Cl} \\
(\text { meg. })\end{array}$ & $\begin{array}{c}\mathrm{Na} \\
(\mathrm{meq} \cdot)\end{array}$ & $\begin{array}{c}K \\
\left(m \infty q_{0}\right) \\
\end{array}$ & $\left(g^{n}\right)$ \\
\hline BB & $\begin{array}{r}0-3 \\
3-6 \\
6-7 \\
7-10 \\
10-13 \\
\end{array}$ & $\begin{array}{r}0 \\
0 \\
0 \\
40 \\
40 \\
\end{array}$ & $\begin{array}{l}9.52 \\
9.54 \\
3.23 \\
9.97 \\
9.52\end{array}$ & $\begin{array}{r}268 \\
268 \\
89 \\
282 \\
279 \\
\end{array}$ & $\begin{array}{r}225 \\
225 \\
75 \\
681 \\
678 \\
\end{array}$ & $\begin{array}{l}320 \\
320 \\
107 \\
337 \\
333 \\
\end{array}$ & $\begin{array}{l}46.7 \\
46.7 \\
25.6 \\
49.1 \\
48.6 \\
\end{array}$ & $\begin{array}{l}5.80 \\
4.35 \\
1.70 \\
4.32 \\
5.55\end{array}$ & $\begin{array}{r}312 \\
157 \\
64 \\
169 \\
264\end{array}$ & $\begin{array}{r}330 \\
167 \\
49 \\
332 \\
\end{array}$ & $\begin{array}{r}212 \\
224 \\
81 \\
130 \\
- \\
\end{array}$ & $\begin{array}{l}35.4 \\
36.1 \\
13.1 \\
33.1 \\
42.7\end{array}$ & 816 & 11 & $\begin{array}{r}19 \\
466\end{array}$ & $\begin{array}{l}103 \\
236\end{array}$ & $\begin{array}{l}6.6 \\
4.9\end{array}$ \\
\hline $\boldsymbol{N}$ & $\begin{array}{r}0-3 \\
3-6 \\
6-7 \\
7-10 \\
10-13 \\
\end{array}$ & $\begin{array}{r}0 \\
0 \\
0 \\
40 \\
40 \\
\end{array}$ & $\begin{array}{r}10.56 \\
10.05 \\
3.23 \\
9.83 \\
9.71 \\
\end{array}$ & $\begin{array}{r}268 \\
279 \\
89 \\
272 \\
274 \\
\end{array}$ & $\begin{array}{r}225 \\
234 \\
75 \\
672 \\
674 \\
\end{array}$ & $\begin{array}{l}320 \\
333 \\
107 \\
325 \\
327\end{array}$ & $\begin{array}{l}46.7 \\
48.6 \\
15.6 \\
47.4 \\
47.7\end{array}$ & $\begin{array}{l}5.60 \\
3.76 \\
1.51 \\
2.99 \\
4.61 \\
\end{array}$ & $\begin{array}{r}303 \\
123 \\
74 \\
84 \\
- \\
\end{array}$ & $\begin{array}{r}213 \\
77 \\
54 \\
344 \\
- \\
\end{array}$ & $\begin{array}{r}261 \\
184 \\
83 \\
144 \\
- \\
\end{array}$ & $\begin{array}{l}34.6 \\
27.9 \\
11.0 \\
27.0 \\
32.0 \\
\end{array}$ & $\pi 4$ & 4 & $\begin{array}{r}27 \\
192\end{array}$ & $\begin{array}{r}103 \\
74\end{array}$ & $\begin{array}{l}9.6 \\
2.9\end{array}$ \\
\hline$\sqrt{B}$ & $0-8$ & 40 & 22.45 & 295 & 1201 & 726 & 123.5 & 16.70 & 233 & 411 & 180 & 206.2 & 2021 & 12 & 605 & 446 & h6.2 \\
\hline
\end{tabular}


TABLE XI

Intake data and urine and stool output in subjects receiving cation exchanger in the $K$ cycle

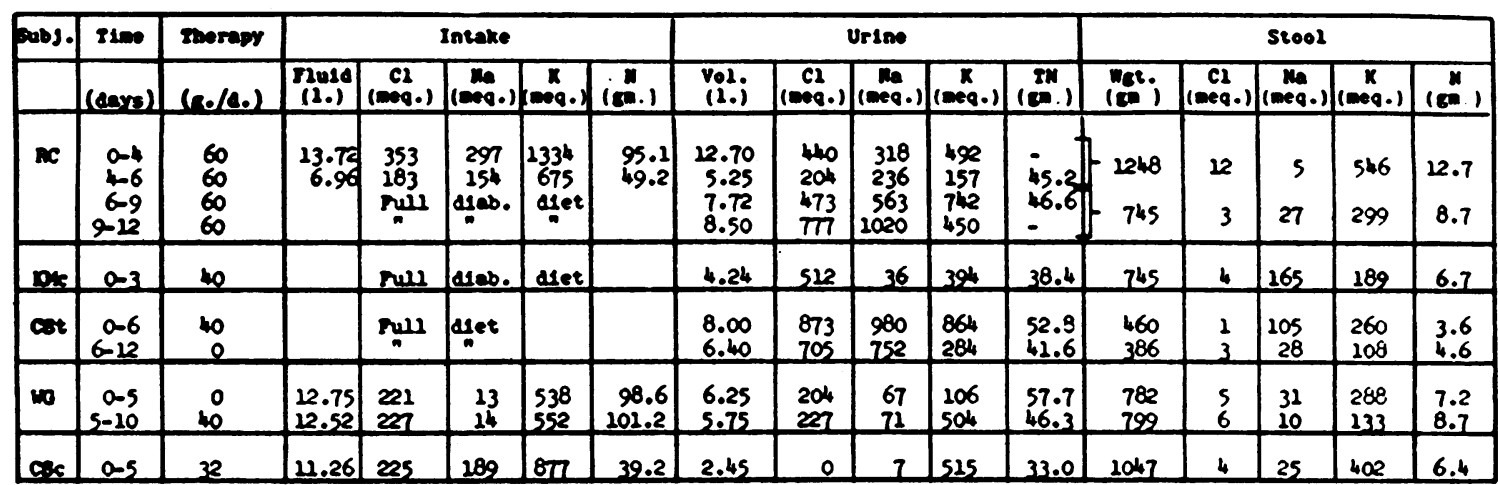

TABLE XII

External, extracellular, and cell balances in subjects receiving the cation exchanger in the Na cycle

\begin{tabular}{|c|c|c|c|c|c|c|c|c|c|c|c|c|c|}
\hline \multirow[t]{2}{*}{ Subject } & \multirow{2}{*}{$\frac{2100}{\left(D_{2}\right)}$} & \multirow{2}{*}{$\begin{array}{l}\text { Therapy } \\
\text { (s./d.) }\end{array}$} & \multicolumn{4}{|c|}{ Ext. Bal. } & \multicolumn{3}{|c|}{ Extracell. Bal. } & \multicolumn{3}{|c|}{ Cell Dal. } & \\
\hline & & & $\begin{array}{c}\mathrm{Cl} \\
\text { (med.) }\end{array}$ & $\ln _{\text {(neq.) }}$ & $\begin{array}{c}K \\
(m 0,0)\end{array}$ & $\left(\operatorname{sg}^{n}\right)$ & $\begin{array}{l}H_{2} 0 \\
(1 .)\end{array}$ & (mea.) & $\begin{array}{c}x \\
(\mathbf{m e q} \cdot)\end{array}$ & $\left(g^{n}\right)$ & (me.) & $\begin{array}{c}K \\
(m e 0 .)\end{array}$ & \\
\hline $\mathbf{B}$ & $\begin{array}{r}0-3 \\
3-6 \\
6-7 \\
7-10 \\
10-13 \\
\end{array}$ & $\begin{array}{r}0 \\
0 \\
0 \\
40 \\
40 \\
\end{array}$ & $\begin{array}{r}51 \\
+104 \\
+21 \\
+210 \\
+12 \\
\end{array}$ & $\begin{array}{r}-117 \\
+46 \\
120 \\
+122 \\
- \\
\end{array}$ & $\begin{array}{r}+64 \\
+52 \\
+11 \\
+88 \\
- \\
\end{array}$ & $\begin{array}{r}8.3 \\
+7.6 \\
+1.0 \\
+13.2 \\
+\quad 3.2 \\
\end{array}$ & $\begin{array}{c}-0.5 \\
40.8 \\
-0.3 \\
+1.4 \\
0 \\
\end{array}$ & $\begin{array}{r}+18 \\
+69 \\
-58 \\
+153 \\
+59 \\
\end{array}$ & $\begin{array}{r}+1 \\
+10 \\
-12 \\
+7 \\
+4 \\
\end{array}$ & $\begin{array}{r}+7.3 \\
+7.9 \\
-0.7 \\
+14.9 \\
+\quad 3.2 \\
\end{array}$ & $\begin{array}{r}-135 \\
-23 \\
+78 \\
-41 \\
- \\
\end{array}$ & $\begin{array}{r}+63 \\
+\quad 12 \\
+23 \\
+81 \\
- \\
\end{array}$ & $\begin{array}{r}+46 \\
+23 \\
+25 \\
+45 \\
- \\
\end{array}$ \\
\hline $\boldsymbol{N}$ & $\begin{array}{r}0-3 \\
3-6 \\
6-7 \\
7-10 \\
\end{array}$ & $\begin{array}{r}0 \\
0 \\
0 \\
40 \\
\end{array}$ & $\begin{array}{r}40 \\
+151 \\
+12 \\
+183 \\
\end{array}$ & $\begin{array}{r}-3 \\
+142 \\
+14 \\
+324 \\
\end{array}$ & $\begin{array}{r}125 \\
+205 \\
+\quad 9 \\
+245\end{array}$ & $\begin{array}{r}7.6 \\
+16.2 \\
+2.9 \\
+18.6 \\
\end{array}$ & $\begin{array}{l}-0.5 \\
+1.2 \\
+0.1 \\
+1.6 \\
\end{array}$ & $\begin{array}{r}114 \\
+123 \\
+15 \\
+234 \\
\end{array}$ & $\begin{array}{r}+5 \\
+3 \\
+12 \\
-5 \\
\end{array}$ & $\begin{array}{r}+6.2 \\
+17.3 \\
+2.2 \\
+19.3 \\
\end{array}$ & $\begin{array}{l}-17 \\
+19 \\
-1 \\
+80 \\
\end{array}$ & $\begin{array}{r}10 \\
+202 \\
+\quad 3 \\
+240 \\
\end{array}$ & $\begin{array}{l}-5 \\
+61 \\
-8 \\
48\end{array}$ \\
\hline$\sqrt[V B]{ }$ & $0-8$ & 40 & +48 & +182 & +89 & +0.8 & 10.7 & +134 & +2 & +2.0 & +48 & +8 & 475 \\
\hline
\end{tabular}

* Corrected for balance of NPN

** Represents transfers of $\mathrm{K}$ in excess of the anabolism and catabolism of protein

TABLE XIII

External, extracellular, and cell balances in subjects receiving cation exchanger in the $K$ cycle

\begin{tabular}{|c|c|c|c|c|c|c|c|c|c|c|c|c|c|}
\hline \multirow[t]{2}{*}{ Ansect } & \multirow{2}{*}{ 210 } & \multirow{2}{*}{$\frac{\text { merags }}{\left(\mathrm{c}_{0} / \mathrm{a}_{0}\right)}$} & \multicolumn{4}{|c|}{ Ixt. Bal. } & \multicolumn{3}{|c|}{ Ixerace 21. Bal. } & \multicolumn{3}{|c|}{ Cell Dal. } & \multirow[b]{2}{*}{ is } \\
\hline & & & (nseg.) & (mea.) & $\begin{array}{c}x \\
(\operatorname{mog} .)\end{array}$ & (E.) & $\begin{array}{c}18,0 \\
(2 .)\end{array}$ & $(m e$, & $\begin{array}{c}X \\
\text { (meq.) }\end{array}$ & $\left(\theta_{0}\right)$ & (meq.) & $\begin{array}{c}x \\
(m e q .) \\
\end{array}$ & \\
\hline EC & & $\begin{array}{l}60 \\
60 \\
\end{array}$ & $\begin{array}{l}-99 \\
-21 \\
\end{array}$ & $\begin{array}{l}-28 \\
-81 \\
\end{array}$ & $\begin{array}{r}178 \\
+336 \\
\end{array}$ & -0.5 & $\begin{array}{l}-1.2 \\
-0.1 \\
\end{array}$ & $\begin{array}{r}-270 \\
0 \\
\end{array}$ & $\begin{array}{l}-24 \\
-1 \\
\end{array}$ & 10.1 & $\begin{array}{l}1212 \\
-81 \\
\end{array}$ & $\begin{array}{l}4492 \\
1337\end{array}$ & 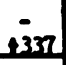 \\
\hline$\omega$ & $\begin{array}{r}0-5 \\
5=10\end{array}$ & $\begin{array}{r}0 \\
10 \\
\end{array}$ & $\begin{array}{r}10 \\
-\quad 8 \\
\end{array}$ & $\begin{array}{l}-89 \\
-72 \\
\end{array}$ & $\begin{array}{l}1244 \\
-85 \\
\end{array}$ & $\begin{array}{r}+33.4 \\
+45.9 \\
\end{array}$ & $\begin{array}{r}10.3 \\
+0.2 \\
\end{array}$ & $\begin{array}{r}20 \\
+\quad 68 \\
\end{array}$ & $\begin{array}{r}2 \\
+\quad 3 \\
\end{array}$ & $\begin{array}{r}42.0 \\
1 \times 6.7\end{array}$ & $\begin{array}{l}-109 \\
-139 \\
\end{array}$ & $\begin{array}{r}142 \\
-88 \\
\end{array}$ & $\begin{array}{l}46 \\
-298 \\
\end{array}$ \\
\hline ex: & $0-5$ & $m$ & 1.927 & 159 & -40 & -0.8 & 12.7 & 1288 & 188 & -0.5 & -236 & -68 & \\
\hline
\end{tabular}

* Value has been corrected for external balance of NPN

** Represents transfers of $\mathrm{K}$ in excess of protein metabolism

bohydrate metabolism. In view of the inherent variations in carbohydrate utilization from day to day, even in well-regulated diabetic patients, only this general statement is justified. The possibility of some influence of the acidosis, such as that described in dogs receiving ammonium chloride (4), cannot therefore be excluded.
Several of the studies were conducted in patients with edema. WK in Tables I, III, and VI is of particular interest in this respect because on a combination of marked sodium restriction and resin therapy his body weight dropped $5.6 \mathrm{~kg}$. in nine days. The stool sodium excretion during this interval totaled 88 meq. It is obvious that this de- 
TABLE XIV

Intake data and urine and stool output in subjects receiving the cation exchanger in the Ca cycle

\begin{tabular}{|c|c|c|c|c|c|c|c|c|c|c|c|c|c|c|c|c|c|c|}
\hline \multirow{2}{*}{ Subs. } & \multirow{2}{*}{$\begin{array}{c}\text { Inse } \\
\text { (dars) }\end{array}$} & \multirow{2}{*}{ Itwerapy } & \multicolumn{5}{|c|}{ Intake } & \multicolumn{6}{|c|}{ Urine } & \multicolumn{5}{|c|}{ Stool } \\
\hline & & & $\begin{array}{c}\text { Tluid } \\
(1 .)\end{array}$ & $\begin{array}{c}C 2 \\
(m e q,) \\
\end{array}$ & $\begin{array}{c}\mathrm{Ma} \\
(\mathrm{meq})\end{array}$ & $\begin{array}{c}\mathrm{K} \\
(\mathrm{meg},)\end{array}$ & $\left(\mathbf{g}^{n}.\right)$ & $\begin{array}{l}\text { Vol. } \\
(1 .)\end{array}$ & \begin{tabular}{c|}
$C 2$ \\
$(m e q)$. \\
\end{tabular} & $\begin{array}{c}m a \\
(m 09 .) k\end{array}$ & $\begin{array}{c}x \\
(009 \cdot) \\
\end{array}$ & (gin.) & 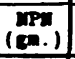 & $\begin{array}{l}\text { Wet; } \\
\text { (gin ) }\end{array}$ & $\begin{array}{c}\text { Cl } \\
\text { (meq. }) \\
\end{array}$ & $\begin{array}{c}\operatorname{ma}_{(\mathrm{m}} \\
(\mathrm{mog}) \\
\end{array}$ & \begin{tabular}{c|} 
\\
$($ meq. \\
\end{tabular} & $\left(\cos ^{n}\right)$ \\
\hline VB & $\begin{array}{l}0-2 \\
2-8 \\
\end{array}$ & $\begin{array}{r}0 \\
40 \\
\end{array}$ & $\begin{array}{r}4.77 \\
25.14\end{array}$ & $\begin{array}{r}74 \\
221 \\
\end{array}$ & $\begin{array}{r}4 \\
23\end{array}$ & $\begin{array}{l}179 \\
537 \\
\end{array}$ & $\begin{array}{l}21.2 \\
22.6 \\
\end{array}$ & $\begin{array}{r}1.71 \\
11.20 \\
\end{array}$ & $\begin{array}{r}44 \\
242 \\
\end{array}$ & 110 & 226 & $\begin{array}{l}13.5 \\
90.5\end{array}$ & & & $\mathcal{U}$ & 32 & 237 & 11.7 \\
\hline $\boldsymbol{J}$ & $\begin{array}{r}0-5 \\
5-11 \\
11-17 \\
17-23 \\
\end{array}$ & $\begin{array}{r}0 \\
40 \\
0 \\
40 \\
\end{array}$ & $\begin{array}{l}15.57 \\
26.69 \\
\end{array}$ & $\begin{array}{l}\text { rul } \\
365 \\
709\end{array}$ & $\begin{array}{l}\text { arab. } \\
306 \\
595\end{array}$ & $\begin{array}{l}\text { det } \\
436 \\
847 \\
\end{array}$ & $\begin{array}{r}97.7 \\
123.6 \\
\end{array}$ & $\begin{array}{r}8.25 \\
14.95 \\
9.15 \\
\mathcal{u} .50 \\
\end{array}$ & $\begin{array}{r}480 \\
1809 \\
380 \\
430 \\
\end{array}$ & $\begin{array}{r}1258 \\
1742 \\
345 \\
309 \\
\end{array}$ & $\begin{array}{l}349 \\
168 \\
390 \\
421 \\
\end{array}$ & $\begin{array}{c}63.2 \\
- \\
72.5 \\
97.3\end{array}$ & $\begin{array}{l}- \\
- \\
-\end{array}$ & $\begin{array}{r}1457 \\
472 \\
647 \\
\end{array}$ & $\begin{array}{l}6 \\
5 \\
6 \\
\end{array}$ & $\begin{array}{r}61 \\
12 \\
8 \\
\end{array}$ & $\begin{array}{r}253 \\
61 \\
99 \\
\end{array}$ & $\begin{array}{c}9.0 \\
5.5 \\
\end{array}$ \\
\hline $\operatorname{cst}$ & $\begin{array}{r}0-6 \\
6-12 \\
\end{array}$ & $\begin{array}{r}0 \\
40 \\
\end{array}$ & & Pull & diet & & & $\begin{array}{l}7.40 \\
6.50 \\
\end{array}$ & $\begin{array}{r}936 \\
778 \\
\end{array}$ & $\begin{array}{l}907 \\
681 \\
\end{array}$ & $\begin{array}{l}335 \\
246 \\
\end{array}$ & $\begin{array}{l}45.1 \\
38.2 \\
\end{array}$ & - & $\begin{array}{l}291 \\
463 \\
\end{array}$ & $\begin{array}{l}2 \\
3\end{array}$ & $\begin{array}{r}205 \\
46 \\
\end{array}$ & $\begin{array}{l}83 \\
82\end{array}$ & $\begin{array}{l}2.0 \\
4.4\end{array}$ \\
\hline DY & $\begin{array}{r}0-6 \\
6-12 \\
u-16 \\
\end{array}$ & $\begin{array}{l}50 \\
60 \\
60 \\
\end{array}$ & & 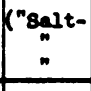 & $\begin{array}{c}\text { eree } \\
\infty\end{array}$ & $\begin{array}{c}\text { det } \\
n \\
\end{array}$ & & $\begin{array}{l}12.50 \\
10.40 \\
21.00 \\
\end{array}$ & $\begin{array}{r}421 \\
219 \\
0 \\
\end{array}$ & $\begin{array}{l}413 \\
201 \\
217 \\
\end{array}$ & $\begin{array}{l}249 \\
251 \\
298 \\
\end{array}$ & $\begin{array}{l}59.5 \\
55.6 \\
54.8 \\
\end{array}$ & $\begin{array}{l}53.5 \\
44.8 \\
47.6 \\
\end{array}$ & $\begin{array}{r}1229 \\
1003 \\
961 \\
\end{array}$ & $\begin{array}{r}14 \\
7 \\
\end{array}$ & $\begin{array}{r}108 \\
58 \\
46 \\
\end{array}$ & $\begin{array}{l}54 \\
82 \\
94\end{array}$ & $\begin{array}{l}6.8 \\
8.8 \\
9.0 \\
\end{array}$ \\
\hline
\end{tabular}

TABLE XV

Body weight and analyses of blood and serum in subjects receiving the cation exchanger in the Ca cycle

\begin{tabular}{|c|c|c|c|c|c|c|c|c|c|c|c|c|c|}
\hline Subject & Ilwe & Therapy & Body WBt. & \multicolumn{2}{|c|}{$8100 d$} & \multicolumn{8}{|c|}{ Serum } \\
\hline$\left(A_{B O}-S_{O X}\right)$ & (Days) & $\left(g_{\cdot} / d_{0}\right)$ & (kB.) & \begin{tabular}{|c|} 
Sug.ar \\
(mgax) \\
\end{tabular} & $\begin{array}{c}\text { NPN } \\
\text { (mgans) } \\
\end{array}$ & $\begin{array}{c}\mathrm{HCO} \\
\text { (meq./1.) }\end{array}$ & $\begin{array}{c}C 1 \\
(\operatorname{seq} . / 1 .) \\
\end{array}$ & $\frac{\mathrm{Na}}{(\operatorname{meg} \cdot / 1 .)}$ & $\begin{array}{c}\mathrm{K} \\
(\mathrm{meq} \cdot / 1 .) \\
\end{array}$ & $\begin{array}{c}\mathrm{Ca} \\
(\operatorname{mog} x)\end{array}$ & $\stackrel{P}{(\operatorname{mgses})}$ & $\begin{array}{c}H, 0 \\
(8 . / 2 .)\end{array}$ & $\begin{array}{c}\text { Proteld } \\
(8, \pi)\end{array}$ \\
\hline 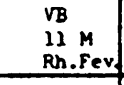 & $\begin{array}{r}0 \\
0-2 \\
2-8 \\
\end{array}$ & $\begin{array}{r}0 \\
0 \\
40 \\
\end{array}$ & $\begin{array}{l}37.1 \\
36.9 \\
36.6 \\
\end{array}$ & $\begin{array}{r}91 \\
102 \\
75 \\
\end{array}$ & $\begin{array}{l}29 \\
38 \\
35 \\
\end{array}$ & $\begin{array}{l}25.7 \\
24.7 \\
24.0 \\
\end{array}$ & $\begin{array}{l}101.5 \\
102.0 \\
100.0 \\
\end{array}$ & $\begin{array}{l}145 \\
239 \\
\end{array}$ & $\begin{array}{l}. \\
4.2 \\
3.5 \\
\end{array}$ & $\begin{array}{l}- \\
- \\
\end{array}$ & $\begin{array}{l}4.6 \\
5.4 \\
4.3 \\
\end{array}$ & $\begin{array}{l}924 \\
920 \\
923 \\
\end{array}$ & $\begin{array}{l}8.0 \\
8.9 \\
8.0 \\
\end{array}$ \\
\hline $\begin{array}{l}\text { J } \\
29 \text { M } \\
\text { Diab. }\end{array}$ & $\begin{array}{r}0 \\
0-5 \\
5-11 \\
12-17 \\
11-23\end{array}$ & $\begin{array}{r}1 \\
0 \\
40 \\
0 \\
40 \\
\end{array}$ & $\begin{array}{l}68.5 \\
69.5 \\
67.6 \\
67.6 \\
67.6 \\
\end{array}$ & $\begin{array}{r}45 \\
98 \\
168 \\
37 \\
- \\
\end{array}$ & $\begin{array}{l}39 \\
41 \\
37 \\
32 \\
37\end{array}$ & $\begin{array}{l}28.3 \\
26.9 \\
28.9 \\
29.3 \\
27.8 \\
\end{array}$ & $\begin{array}{r}101.2 \\
98.6 \\
96.7 \\
96.8 \\
93.6 \\
\end{array}$ & $\begin{array}{l}146 \\
145 \\
149 \\
140 \\
134 \\
\end{array}$ & $\begin{array}{l}5.1 \\
5.3 \\
4.8 \\
3.4 \\
3.3 \\
\end{array}$ & $\begin{array}{c}10.1 \\
9.9 \\
- \\
10.9 \\
9.9\end{array}$ & $\begin{array}{c}4.0 \\
3.0 \\
0 \\
3.9 \\
- \\
\end{array}$ & $\begin{array}{l}\dddot{21} \\
925 \\
928 \\
926 \\
928 \\
\end{array}$ & $\begin{array}{l}- \\
7.3 \\
7.0 \\
6.8 \\
7.2 \\
\end{array}$ \\
\hline $\begin{array}{l}\text { CSt } \\
\text { ShM M } \\
\text { Artir. }\end{array}$ & $\begin{array}{r}0 \\
0-6 \\
6-12 \\
\end{array}$ & $\begin{array}{r}0 \\
40 \\
\end{array}$ & - & $\frac{105}{\pi}$ & $\begin{array}{l}32 \\
30 \\
28 \\
\end{array}$ & $\begin{array}{l}26.3 \\
27.2 \\
27.2 \\
\end{array}$ & $\begin{array}{l}104.9 \\
102.0 \\
100.3\end{array}$ & $\begin{array}{l}143 \\
143 \\
144 \\
\end{array}$ & $\begin{array}{l}5.0 \\
4.5 \\
3.9 \\
\end{array}$ & $\begin{array}{l}9.3 \\
9.2 \\
9.2 \\
\end{array}$ & $\begin{array}{l}3.2 \\
2.7 \\
3.4 \\
\end{array}$ & $\begin{array}{l}934 \\
931 \\
937 \\
\end{array}$ & $\begin{array}{l}6.8 \\
6.9 \\
6.5 \\
\end{array}$ \\
\hline $\begin{array}{l}\text { DY } \\
\text { I2 M } \\
\text { Nephro }\end{array}$ & $\begin{array}{r}0 \\
0-6 \\
6-11 \\
11-16 \\
\end{array}$ & $\begin{array}{l}50 \\
60 \\
60 \\
\end{array}$ & $\begin{array}{l}28.4 \\
29.6 \\
30.6 \\
\end{array}$ & $\begin{array}{l}89 \\
- \\
- \\
-\end{array}$ & $\begin{array}{l}45 \\
39 \\
38 \\
38 \\
\end{array}$ & $\begin{array}{l}17.3 \\
21.5 \\
21.3 \\
23.1 \\
\end{array}$ & $\begin{array}{l}108.0 \\
104.6 \\
104.1 \\
101.7 \\
\end{array}$ & $\begin{array}{l}135 \\
136 \\
143 \\
141 \\
\end{array}$ & $\begin{array}{l}3.9 \\
4.1 \\
4.1 \\
3.9\end{array}$ & $\begin{array}{l}7.8 \\
8.2 \\
8.4 \\
7.6\end{array}$ & $\begin{array}{l}4.5 \\
4.5 \\
4.8 \\
4.6 \\
\end{array}$ & $\begin{array}{l}921 \\
925 \\
933 \\
929\end{array}$ & $\begin{array}{l}4.3 \\
4.3 \\
3.8 \\
3.8 \\
\end{array}$ \\
\hline$\sum_{\text {Rephro }}^{\text {M. }}$ & $\begin{array}{r}0 \\
0-5 \\
5-10 \\
10-16 \\
\end{array}$ & $\begin{array}{l}4 \\
40 \\
33\end{array}$ & $\begin{array}{c}21.0 \\
- \\
- \\
\end{array}$ & $\therefore$ & $\begin{array}{l}28 \\
36 \\
32 \\
31 \\
\end{array}$ & $\begin{array}{l}24.1 \\
22.6 \\
20.9 \\
20.7 \\
\end{array}$ & $\begin{array}{r}102.3 \\
99.8 \\
103.7 \\
102.7 \\
\end{array}$ & $\begin{array}{l}139 \\
135 \\
138 \\
134 \\
\end{array}$ & $\begin{array}{l}3.8 \\
4.1 \\
4.4 \\
4.0 \\
\end{array}$ & $\begin{array}{c}8.6 \\
7.5 \\
- \\
\end{array}$ & $\begin{array}{c}5.3 \\
5.7 \\
0 \\
5.0\end{array}$ & $\begin{array}{l}928 \\
935 \\
935\end{array}$ & $\begin{array}{l}3.9 \\
3.7 \\
4.0 \\
3.9\end{array}$ \\
\hline
\end{tabular}

* End of $\mathrm{H}$ and $\mathrm{K}$ resin period

** End of $\mathrm{NH}_{4}$ and $\mathrm{K}$ resin period

TABLE XVI

External, extracellular, and cell balances in subjects receiving the cation exchanger in the Ca cycle

\begin{tabular}{|c|c|c|c|c|c|c|c|c|c|c|c|c|c|}
\hline \multirow[t]{2}{*}{ Subject } & \multirow{2}{*}{$\begin{array}{l}\text { Tiee } \\
\text { (Days) }\end{array}$} & \multirow{2}{*}{$\frac{\text { Therapy }}{(\mathrm{s} \cdot / \mathrm{d} .)}$} & \multicolumn{4}{|c|}{ Ext. Bal. } & \multicolumn{3}{|c|}{ Extracell. Bal. } & \multicolumn{3}{|c|}{ Cell Bal. } & \multirow[b]{2}{*}{$\begin{array}{l}\mathrm{K}-1 \\
\text { feq. }\end{array}$} \\
\hline & & & $\begin{array}{c}\mathrm{Cl} \\
(\mathrm{aeq})\end{array}$ & $\begin{array}{c}\text { Ma } \\
\text { (neg.) }\end{array}$ & $\begin{array}{c}\mathrm{K} \\
\text { (meg.) }\end{array}$ & $\left(g^{N}\right)$ & $\begin{array}{l}4,0 \\
(1 .)\end{array}$ & $\underset{(n 0,}{100}$ & $\begin{array}{c}X \\
(m e q .)\end{array}$ & (gm.) & $\begin{array}{c}\text { Ma } \\
\text { (neq.) }\end{array}$ & $\underset{\text { (med.) }}{-k}$ & \\
\hline$\sqrt{B}$ & $\begin{array}{l}0-2 \\
2-8 \\
\end{array}$ & $\begin{array}{r}0 \\
40 \\
\end{array}$ & $\begin{array}{r}+24 \\
-\quad 31 \\
\end{array}$ & -224 & +133 & $\begin{array}{r}+4.5 \\
-7.0 \\
\end{array}$ & -0.1 & -69 & -6 & -6.3 & -55 & +139 & +154 \\
\hline $\boldsymbol{T}$ & $\begin{array}{l}11-17 \\
17-23\end{array}$ & $\begin{array}{r}0 \\
40\end{array}$ & $\begin{array}{r}-22 \\
+271 \\
\end{array}$ & $\begin{array}{r}-55 \\
+274\end{array}$ & $\begin{array}{r}-15 \\
+327\end{array}$ & +20.5 & $\begin{array}{r}-0.2 \\
+3.0 \\
\end{array}$ & $\begin{array}{r}-150 \\
+327\end{array}$ & $\begin{array}{r}-21 \\
+7\end{array}$ & $+2 \overline{6} .3$ & $\begin{array}{r}95 \\
+181 \\
\end{array}$ & $\begin{array}{r}+6 \\
+320 \\
\end{array}$ & $+\ddot{+276}$ \\
\hline
\end{tabular}

* Value has been corrected for external balance of NPN

** Represents transfers of $\mathrm{K}$ in excess of protein metabolism 
crease in endogenous sodium as a result of stool losses could not by itself account for the extensive decrease of edema. The bulk of the sodium was lost in urine. It seems probable that the additive effect of the acidosis should be listed among other factors contributory to this diuresis.

On the other hand in patient CSc in the same tables much larger amounts of sodium were excreted in stools during the administration of the exchanger together with a milk diet unrestricted as to sodium. It is reasonable to suggest that without resin to interfere with the absorption of the ingested sodium this patient would not have lost edema fluid. Patient GDe demonstrates the degree to which the efficacy of the resin in augmenting stool sodium can vary not only from patient to patient, but also in the same subject. In the 10 to 15 day period he lost much less sodium per day in stool than in the somewhat longer 19 to 25 day interval. In this patient it is again worth pointing out that his initial huge diuresis with a body weight loss of $9.9 \mathrm{~kg}$. cannot be attributed to stool losses of sodium, but that the marked acidosis which appeared during resin therapy may have hastened the delivery of the edema fluid.

Finally it should be pointed out that these exchangers have been administered to patients with renal failure. These can be most readily identified by the elevated blood nonprotein nitrogen values in the various tables of serum and blood data. The fact that in this series no complications developed such as clinical acidosis or potassium intoxication does not mean that these exchangers can be used with impunity in all forms of renal disease. The risks and benefits have been described in greater detail in another paper in this series (5). Insofar as the current studies are concerned it should be emphasized that they were of limited duration and interrupted short of undesirable or dangerous changes when certain trends had become well established, as with the acidosis in GDe, Table I. Incidentally, the ammonium released from the ammonium form of the resin apparently does not raise whole blood nonprotein nitrogen, but it may have, in some patients, as in WG, Table IV, raised the output of nitrogen in urine.

\section{DISCUSSION}

The data which have been presented indicate that the hydrogen and the ammonium forms of the resin produce effects which are indistinguishable, including essentially equal tendencies to induce acidosis and to increase the excretion of sodium and potassium in the stool. Furthermore, neither influences the output of nitrogen and chloride via this route. Although the efficiency of these resins is relatively low in vivo, it is clear that they may be useful in reducing the absorption of sodium from the diet so that a patient requiring low sodium therapy could ingest food seasoned with more of this cation. That he could not ingest much larger amounts of salt should be clear from the data indicating that each gram of the hydrogen or ammonium forms will remove only up to 1 meq. of sodium.

These studies also support an interpretation voiced elsewhere (1), i.e., that the acidifying resins produce certain serum effects similar to those which follow the use of diuretics such as ammonium chloride, potassium nitrate, et cetera. This suggests that the diuresis accompanying hydrogen or ammonium cycle resin therapy of patients cannot be augmented by the use of acidifying diuretics. On the other hand it is reasonable to predict that mercurial diuretics used in conjunction with these two acidifying resins will exert their maximal effects without the aid of ammonium chloride. There is, however, probably an increased danger of producing potassium depletion under these circumstances which may be counteracted by administration of extra potassium.

Certain extrapolations seem justified with respect to possible clinical application of the sodium and potassium cycle resin findings. The relatively high efficiency of the sodium cycle resin in augmenting the stool output of potassium suggests its possible application in renal insufficiency of the salt-wastage and potassium accumulation type. This agent under such circumstances should augment the external losses of potassium and simultaneously cancel the negative balances of sodium which characterize this disorder (6-8).

The effects of the potassium cycle exchanger suggest that it may be beneficially employed in combination with the hydrogen or ammonium cycle congeners. It is obvious that upon exchange with sodium and hydrogen present in the intestinal tract the released potassium becomes available for absorption and is, as the data indicate, in great measure retained. This effect should serve to cancel 
the deficits of potassium accompanying prolonged use of the hydrogen or ammonium cycle resins without adding to their acidifying effects; although the same purpose may more efficiently be served by increasing dietary potassium intake by means of a salt such as $\mathrm{KHCO}_{3}$ or $\mathrm{KCl}$. The clinical practicality of such combinations has been evaluated elsewhere (9). In addition, the danger of producing potassium intoxication in patients with oliguria and renal disease must be recognized (10-12).

It is possible that certain features of these resins may be utilized in cancelling some of the side effects of prolonged cortisone or ACTH therapy such as alkalosis, sodium retention, and potassium depletion (13-16). For example, combinations of hydrogen and potassium exchangers may be effective in this regard. Potassium depletion, however, may be enhanced under these circumstances unless the intake of potassium is large enough to counteract the combined effects of the resin and ACTH or cortisone on this ion. This problem has been studied in some detail in a subsequent paper (17).

Finally, the lack of any marked effects upon ingestion of the calcium cycle resin is both a disappointment and a reassurance. From the theoretical point of view the resin in this cycle should be useful in far-advanced renal insufficiency: release of the calcium ion from the exchanger should $a$ ) increase stool losses of sodium and of potassium which accumulate in kidney failure, and $b$ ) provide calcium to accelerate phosphate losses as insoluble salts via the bowel and alternatively replace the deficits characteristically present in serum and extracellular fluid of such patients. Unfortunately, neither of these predictions is substantiated by our data. These studies, however, provide a highly satisfactory control for a number of the other reports in this series. The following conclusion is inescapable, if such support be needed: the effects of the ammonium, hydrogen, sodium, and potassium forms of the carboxylic cation exchanger under investigation in this series of studies are attributable to the attached cation and not to the resin itself. If the cation with which the resin is charged is not displaced in sufficient quantity the resin has no detectable effect.

\section{SUM MARY}

1. The ammonium cycle resin produces effects quite comparable to those seen with hydrogen cycle resin ingestion, i.e., hyperchloremia develops, and serum carbon dioxide content falls while the stool sodium and potassium excretion rises.

2. The stool changes seen with either the ammonium or the hydrogen cycle resins are also observed in subjects receiving the exchanger in either the potassium or sodium cycle. In the use of the latter the efficiency in removing potassium is less. Neither consistently affects the serum constituents but occasionally hyperkaliemia appears during potassium resin therapy. With the sodium form of the resin, sodium balances become positive with extracellular retention of this cation. With potassium resin, the intracellular stores of potassium may rise during therapy.

3. In a series of studies on one patient concomitant administration of cortisone did not interfere with the ability of the ammonium resin to raise stool sodium and potassium but hypokaliemia appeared.

4. The calcium cycle of the carboxylic cation exchanger in the form used was relatively inert and produced much smaller changes in stool sodium and potassium. These findings, however, do add support to the view that the cycle of the resin and not the resin per se is the determinative factor in the observed results.

\section{REFERENCES}

1. Danowski, T. S., Greenman, L., Mateer, F. M., Parsons, W. B., Weigand, F. A., Mermelstein, H., and Peters, J. H., Carboxylic cation exchange resin effects in dogs. J. Clin. Invest., 1951, 30, 984.

2. Danowski, T. S., Greenman, L., Mateer, F. M., Peters, J. H., Weigand, F. A., Mermelstein, H., and Clarke, C. E., Carboxylic cation exchange resin studies in animals and humans. J. Clin. Invest., 1950, 29, 807.

3. Danowski, T. S., Cation exchange resins in experimental and clinical situations with special emphasis on edema. Proc. 18th International Physiological Congress, 1950, p. 173.

4. Mackler, B., Lichtenstein, H., and Guest, G. M., Effects of ammonium chloride acidosis on the action of insulin in dogs. Am. J. Physiol., in press.

5. Mateer, F. M., Erhard, L. H., Price, M., Weigand, F A., Peters, J. H., Danowski, T. S., Tarail, R., and Greenman, L., Sodium restriction and cation exchange resin therapy in nephrotic children. $J$. Clin. Invest., 1951, 30, 1018. 
6. Thorn, G. W., Koepf, G. F., and Clinton, M., Jr., Renal failure simulating adrenocortical insufficiency. New England J. Med., 1944, 231, 76.

7. Sawyer, W. H., and Solez, C., Salt-losing nephritis simulating adrenocortical insufficiency. New England J. Med., 1949, 240, 210.

8. Borst, J. R., Disturbances in water and salt metabolism in the final stage of chronic renal insufficiency. Acta med. Scandinav., 1949-50, 136, 1.

9. Greenman, L., Peters, J. H., Mateer, F. M., and Danowski, T. S., Probable clinical utility of cation exchange resins. J. Clin. Invest., 1951, 30, 1027.

10. Keith, N. M., and Burchell, H. B., Clinical intoxication with potassium: its occurrence in severe renal insufficiency. Am. J. M. Sc., 1949, 217, 1.

11. Elkinton, J. R., Tarail, R., and Peters, J. P., Transfers of potassium in renal insufficiency. $\mathrm{J}$. Clin. Invest., 1949, 28, 378.

12. Danowski, T. S., and Elkinton, J. R., Exchanges of potassium related to organs and systems. Pharmacol. Rev., 1951, 3, 42.
13. Elkinton, J. R., Hunt, A. D., Jr., Godfrey, L., McCrory, W. W., Rogerson, A. G., and Stokes, J., Jr., Effects of pituitary adrenocorticotropic hormone (ACTH) therapy. J.A.M.A., 1949, 141, 1273.

14. Ingle, D. J., The biologic properties of cortisone: a review. J. Clin. Endocrinol., 1950, 10, 1312.

15. Sprague, R. G., Power, M. H., Mason, H. L., Albert, A., Mathieson, D. R., Hench, P. S., Kendall, E. C., Slocumb, C. H., and Polley, H. F., Observations on the physiologic effects of cortisone and ACTH in man. Arch. Int. Med., 1950, 85, 199.

16. Greenman, L., Danowski, T. S., Tarail, R., Peters, J. H., Weigand, F. A., and Mateer, F. M., Studies of prevention of some of the toxic effects of prolonged cortisone and ACTH therapy. J. Clin. Invest., 1951, 30, 644.

17. Peters, J. H., Danowski, T. S., Greenman, L., Weigand, F. A., Clarke, C. E., Garver, K., Mateer, F. M., and Tarail, R., Acidifying and non-acidifying carboxylic resin mixtures used alone and with ACTH or cortisone. J. Clin. Invest., 1951, 30, 1009. 